Article

\title{
Microscopic Modeling of Pedestrian Movement in a Shida Night Market Street Segment: Using Vision and Destination Attractiveness
}

\author{
Yun-Shang Chiou* and Ailyne Yap Bayer \\ Department of Architecture, National Taiwan University of Science and Technology, Taipei 106, Taiwan; \\ ailynebayer@gmail.com \\ * Correspondence: ychiou@mail.ntust.edu.tw
}

Citation: Chiou, Y.-S.; Bayer, A.Y.

Microscopic Modeling of Pedestrian Movement in a Shida Night Market Street Segment: Using Vision and Destination Attractiveness.

Sustainability 2021, 13, 8015. https:// doi.org/10.3390/su13148015

Academic Editor: Brian Garrod

Received: 1 June 2021

Accepted: 13 July 2021

Published: 18 July 2021

Publisher's Note: MDPI stays neutral with regard to jurisdictional claims in published maps and institutional affiliations.

Copyright: (C) 2021 by the authors Licensee MDPI, Basel, Switzerland. This article is an open access article distributed under the terms and conditions of the Creative Commons Attribution (CC BY) license (https:/ / creativecommons.org/licenses/by/ $4.0 /)$.

\begin{abstract}
Research has shown that night markets play a positive role in improving urban sustainability. In Taiwan, many people go to night markets for leisurely strolling and to eat out with family and friends. The variety of food choices is a major reason for visiting. This preference and the shops locations affect not only how pedestrians move around but also the business of the night market. Pedestrian vision has been considered in only a minority of studies regarding pedestrian movement in shopping environments. Although some studies have focused on the impulse stops of pedestrians, few have considered "destination attractiveness" and its influence on surrounding shops. This paper aims to improve the pedestrian movement model in night markets with the incorporation of the "destination attractiveness" factor. The proposed microscopy agent-based model, implemented in NetLogo, uses "field of vision" as the possible destinations of the pedestrian's next movement. Inside the "field of vision", each shop competes for the pedestrian's attention based on its "destination attractiveness". The model's parameter values were calibrated and the simulation results were verified with real-world observed data with good agreement. The proposed pedestrian movement model can benefit the retail sector by improving customer satisfaction and profitability by enhancing the layout of the facilities.
\end{abstract}

Keywords: pedestrian simulation; NetLogo; agent-based modeling; visual attraction; vision angles; destination attractiveness; night market; pedestrian behavior

\section{Introduction}

This paper proposes an improved pedestrian movement model in night markets with the incorporation of a "destination attractiveness" factor. The proposed pedestrian movement model can benefit the retail sector by improving customer satisfaction and potentially profitability by enhancing the layout of the facilities.

More than half of the world's population lives in cities, and the number is continuing to increase. Thus, there is a need to study pedestrian movement to make living in cities more comfortable and enjoyable. Living in a bustling city tends to make a person be exhausted from simply going to work; thus, people require leisure activities to refresh and relax their minds. In Taiwan, people visit night markets for leisurely strolling, shopping, and eating out with friends and family. Eating out is considered to be an everyday leisure activity that not only prevents starvation but also satisfies a person's psychological needs [1]. Research has also shown that the night markets play a positive role in improving urban sustainability since "The night market traders are able to increase their incomes which come from lower-middle economic class" [2].

Mainly operating at night in urban or suburban areas, night markets are street markets visited for leisurely strolling, shopping, and eating. Night markets represent the history, society, and economics of Taiwan and provide the "true experience of modern Taiwanese nightlife". Market fairs that sold products near temples or other areas where people 
assemble continually developed into country fairs and later became the night markets known today [3]. Each of the more than 70 night markets in different cities all over Taiwan has its own distinctive established practices, configuration, attributes, and delicacies that represent the local residents [4]. These markets range from tourist destinations to smaller neighborhood markets. This collection of street stalls caters not only to tourists but also to local residents. The night market is a preferred shopping destination because of the variety of local delicacies, entertainment activities, and product offerings [5]. Night markets vary in terms of consumer preferences and the type of food served. These factors also affect where pedestrians go and how they move when strolling in the night market: some areas may have more visitors than others. This common but unique experience sparks interest in research on how visitors' movements are influenced by the variety of food (attractions) and differences in the night market configuration.

Pedestrians explore their environment and take advantage of their surroundings to reach a particular destination, whether in a private or public space. Challenges ranging from functionality and design improvement of public spaces to emergency evacuation continue to be fundamental scientific challenges, despite the abundant studies of pedestrian movement [6]. Substantial research in numerous fields, such as building evacuation, transportation, physics, urban design, and marketing [7-9], has been conducted to determine and predict pedestrian movement with the aid of computer-generated simulations. However, only a few studies have considered the effect on pedestrian behavior with regard to visual perception, especially in a shopping area. Movement and visual perception are interrelated. A person can perceive space through movement and, in turn, movement is affected by the perceived space [10]. The theory of natural movement was investigated through space syntax, which discussed the relationship between configuration, attractors, and movement in the context of an urban grid. In an urban context, attractors are likely to be gathered in a particular location, for instance, shops on a primary business street, wherein it is assumed that the choice of these locations had been configurationally influenced. In this condition, these clusters of attractors likely act as influencers of the fundamental movement pattern created by the configuration. Otherwise, the effects of the attractors can be equalized when evenly distributed. Therefore, movement is an essential ecological behavior created by the interaction between a person and the environment [11].

A few studies using microsimulation to investigate human pedestrian behavior in a built environment have been conducted and have found that human movement can be replicated by encoding Gibson's principle of affordance, creating rules through which an agent chooses a destination within a $170^{\circ}$ visual field, and reassessing every three steps. The exosomal visual architecture (EVA) model was developed to simplify the agent's method of calculating visibility data in real time. This program computes the partial isovist at every grid point [12]. A new natural movement model was proposed with the trajectory of the wall vector field (WVF) model using NetLogo instead the movement trajectory of the EVA model in Depthmap. Movement data were collected from an exhibition space, the Tate Gallery, by comparing the actual tracks of visitors for each area in the gallery for $5 \mathrm{~min}$ 3 times throughout the day. The WVF model produced a better movement pattern than that of the previous model [13]. Another new model based on a navigational pedestrian movement model with vision-driven agents was proposed. In this model, agents use the potential field values of their neighbors to identify the shortest route to a destination. The movement patterns of agents in the proposed model were smoother and more believable than those of a model with blind agents. Furthermore, agents with narrow visual field angles are more likely to miss the shortest path than are agents with wide visual field angles that process more information about the environment [14].

Although recent studies have applied visual perception, the attractiveness of a particular shop or destination has not been considered in determining current and future target destinations. Therefore, this research uses the theory of natural movement [11] to support and analyze the effectiveness of considering pedestrian visual perception and destination attractiveness in determining the shopping behavior of pedestrians in a night market street 
segment through microscopic agent-based simulation. The findings of this research will help expand pedestrian studies and understand the interrelationships among movement, vision, destination attractiveness, and site configuration. This study considers how pedestrian movement is affected by the surroundings. In turn, the environment influences the pedestrian's flow of action in a shopping segment through the application of vision range and shop attractiveness. These factors can help to identify possible visual attractions in night markets or other shopping segments, likewise in spaces that desire attention from pedestrians, such as pop-up stores or seasonal event displays. Field observation in a museum [15] has shown that the visual attractor in an area may help increase visits in areas that do not receive much attention or create a new attraction in the area. Pedestrian modeling can benefit many industries, especially the retail and entertainment sector, to improve customer satisfaction and profitability and enhance the layout of facilities.

\section{Materials and Methods}

This research explores microscopic agent-based modeling (ABM) of pedestrian shopping behavior in a night market street segment via the theory of natural movement [11], individual visual attention range [16], identification of hotspots [17], field observations, data collection, and analysis.

This study is divided into two parts: field observations and analysis through video data collection and reproducing pedestrian movement through microscopic agent-based modeling using NetLogo software (Figure 1).

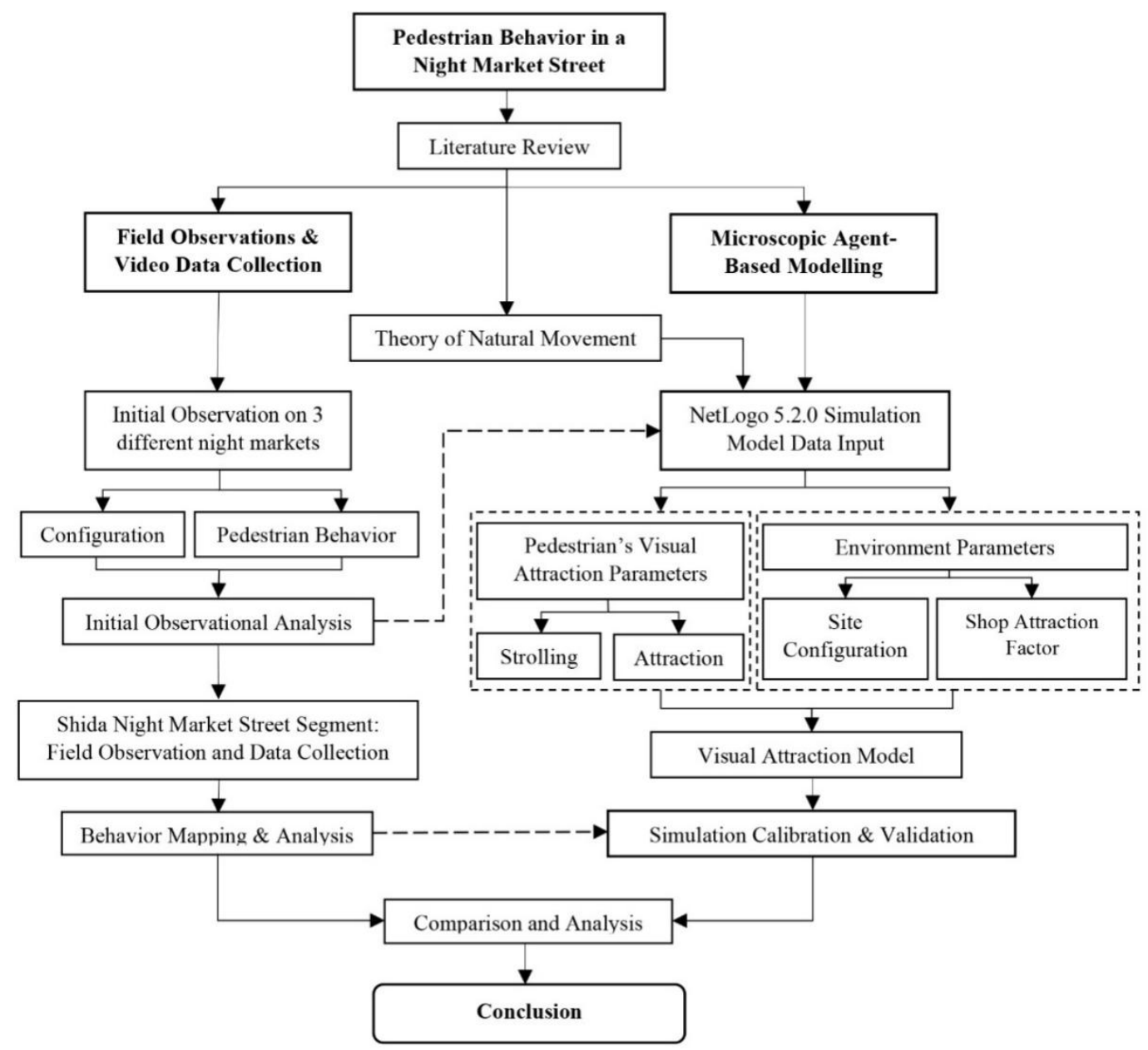

Figure 1. Overall process of the research. 


\subsection{Data Collection and Analysis}

The data collected for this research can be divided into two parts: initial field observations and final field observations for the Shida Night Market street segment. Both observations are accompanied by video data. These field observations and data collections are essential to this research to obtain the parameters that will be inputted into the simulation model.

\subsubsection{Initial Field Observation, Video Data Collection, and Analysis}

To determine and understand pedestrian behavior, three night markets with contrasting layouts located in different cities in Taiwan were selected for the initial field observations. Data collections were conducted for approximately 3 to $5 \mathrm{~h}$ in each night market. The schedule of data collection for each market differed depending on the opening day and the busiest shopping day. For Guanshan, data collection was performed on a Thursday since that is the only day the night market is open. Xiaobei Xinchenggong opens on Tuesdays and Fridays, but data collection was conducted on a Friday, whereas Shida Night Market was observed on a Saturday. Site layout measurements and shop stall identification and video data collection were performed by following selected pedestrians walking from the entrance and strolling through the night market until they departed.

A cross-comparison was performed to determine the similarities and differences of the three night markets (Table 1). The pedestrian's duration of stay differed substantially, with Guanshan Night Market having the shortest visit duration of less than $10 \mathrm{~min}$ and Xiaobei Xinchenggong and Shida Night Markets having longer visit durations of almost one hour. Although the observed group types differed in the on-site observations, all three night markets had individuals, groups of twos and threes, and families. Patrons and casual visitors were observed, in addition to passersby in Shida Night Market. Each segment width was also measured. The Guanshan and Xiaobei Xinchenggong Night Markets have a similar width range of approximately $4 \mathrm{~m}$ at the widest, except for one $0.95 \mathrm{~m}$ walkway in the latter. These two night markets are situated near residential and commercial areas. On the other hand, the Shida Night Market has a wider segment width of $7.61 \mathrm{~m}$ in segment A because it is located within the inner roads of a residential area next to an institutional area.

The three night markets have different user movements due to the differences in layout. The Guanshan Night Market has a loop-type layout; therefore, user movement follows a loop. By contrast, the Xiaobei Xinchenggong Night Market has a grid-type layout, and pedestrians tend to move in a meandering manner. Moreover, the Shida Night Market is straight and branches out; thus, pedestrian movement is linear with stops at intersections to assess where to proceed. The shop compositions of the markets are similar, with food, retail, and games. The buying tendencies are also similar: pedestrians tend to (1) stroll first, then buy and eat while strolling or (2) stroll, sit, and eat, then continue to stroll. A preference for food shops is also prominent in all three night markets, with similar tendencies of entering and exiting at the same point, except in the Shida Night Market, where some pedestrians enter and exit at different points.

The initial observation, data collection, and analysis of the three night markets indicate that contrasting night market layouts results in different pedestrian movements, but as a whole, night markets consist of linear segments and intersection points. Due to limited time and resources, the observation and simulation of pedestrian movement is performed in one of the main segments: movement at intersections will be left for future studies. 
Table 1. Initial observation and data collection cross-comparison for Guanshan, Xiaobei Xinchenggong, and Shida Night Markets.

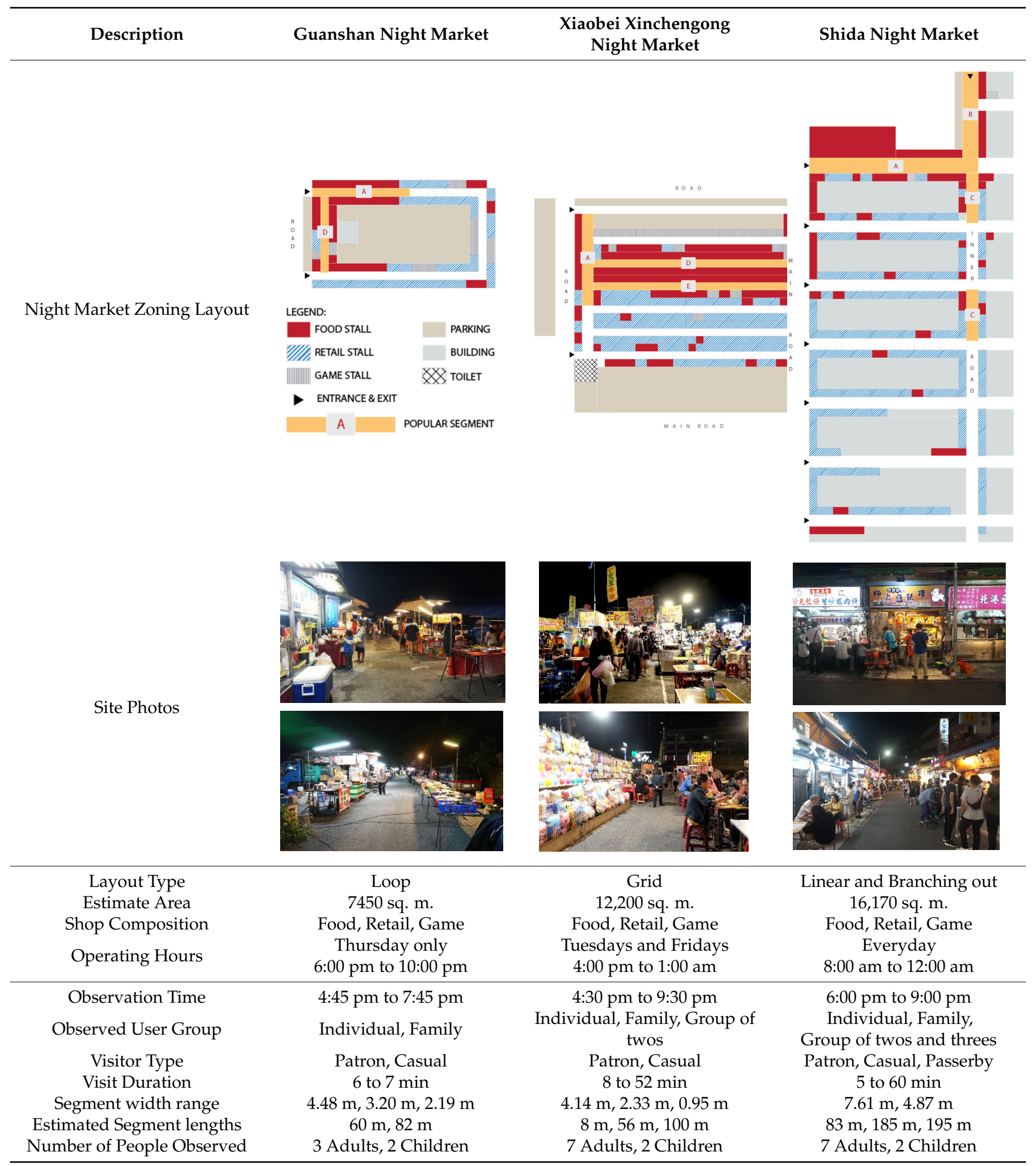


Table 1. Cont.

\begin{tabular}{|c|c|c|c|}
\hline Description & Guanshan Night Market & $\begin{array}{l}\text { Xiaobei Xinchengong } \\
\text { Night Market }\end{array}$ & Shida Night Market \\
\hline User Movement & & שָ & ॠ \\
\hline Shopping preference & $\begin{array}{c}\text { More visitors on segments A } \\
\text { and D which has mostly } \\
\text { food stalls }\end{array}$ & $\begin{array}{l}\text { Meandering } \\
\text { A lot of visitors on segments } \\
\text { with food stalls but starting } \\
\text { from 8:30 and beyond, a lot of } \\
\text { people visit the retail and } \\
\text { game stalls }\end{array}$ & $\begin{array}{c}\longleftrightarrow \\
\text { Linear } \\
\text { A lot of visitors on segments } \\
\text { with food stalls but starting } \\
\text { from 8:30 and beyond, a lot of } \\
\text { people visit the retail and } \\
\text { game stalls }\end{array}$ \\
\hline
\end{tabular}

To explore pedestrian shopping behavior, the final field observation was conducted along one of the street segments of one of the three selected night markets. Shida Night Market's main street segment A was selected for its accessibility and manageability as the final site. The collected video data for this segment were compared to the simulation results.

\subsubsection{Final Field Observation, Video Data Collection Analysis}

Shida Night Market (Figure 2), a night market located within a residential area and near a local university in Taipei City, was selected for the final field observation. The majority of the shops are located on the ground floor of residential buildings, while some are in one-story shops on the university side of the night market.

\section{Field Observation}

Based on the initial observation, segments A, B, and C (Table 1) have the most foot traffic. For this research, street segment A (Figure 3) was chosen for the final field observation and video data collection because it is the night market's entrance segment and has the most pedestrians. Presumably, these pedestrians have not yet been influenced or attracted by other shops.

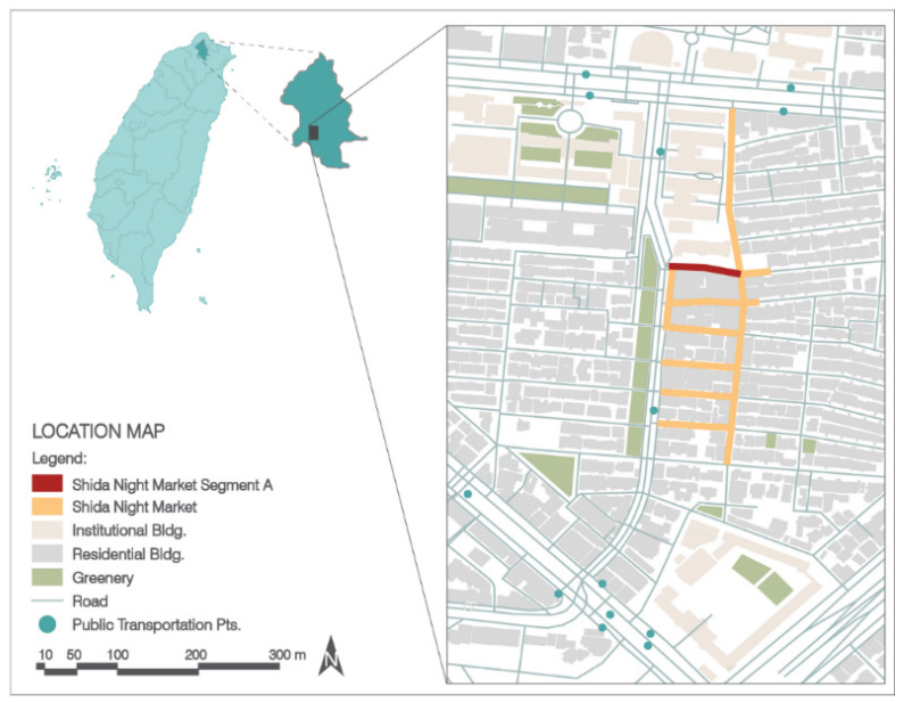

Figure 2. Shida Night Market location map (edited by the author, based on [18]). 


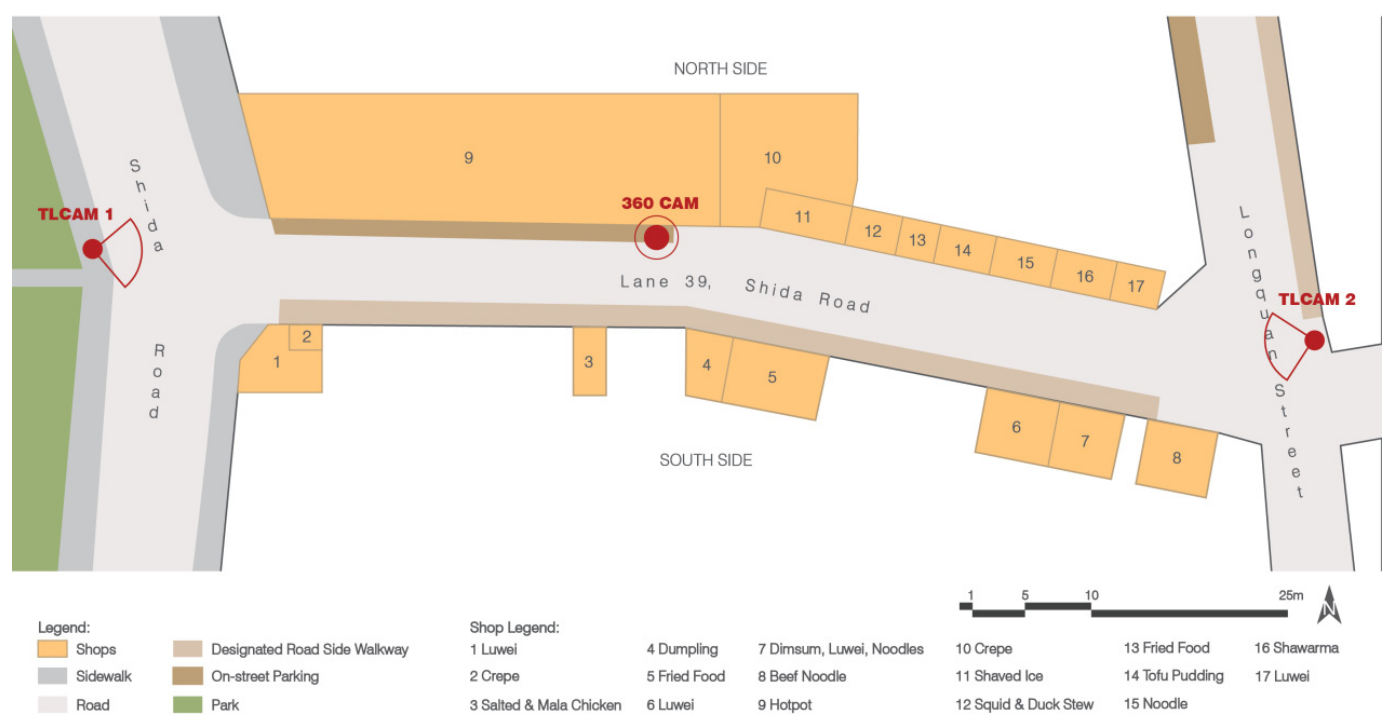

Figure 3. Shida Night Market street segment A layout plan (by author).

Information was gathered through on-site measurement of the segment and shop front widths, shop identification, and elevation photos. Segment A is composed mainly of food shops with some book, appliance, clothing, and game shops. This research focuses on food shops along this street segment. The total length of segment A is approximately $74 \mathrm{~m}$, with an average road width of $7.61 \mathrm{~m}$ along Lane 39 Shida Road, which inclines approximately 11 degrees to meet Longquan Street and $15 \mathrm{~m}$ Shida Road on the left side perpendicular to the segment. This research concentrates on pedestrian visual attraction and shop preferences; therefore, the smell of food when passing through the segment and the depth of the shops are ignored. Segments A-N are shops on the north side of the segment (Figure 4a), and the south side is labeled segment A-S (Figure 4b).

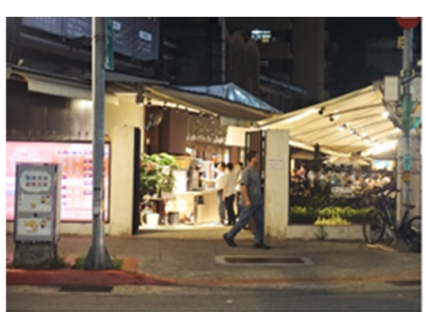

9 Hotpot along Shida Road

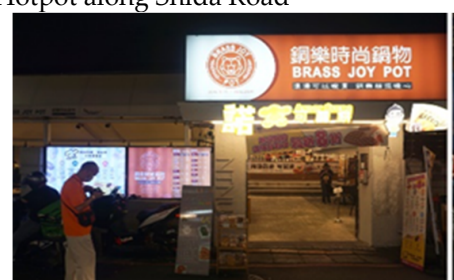

9 Hotpot/10 Crepe

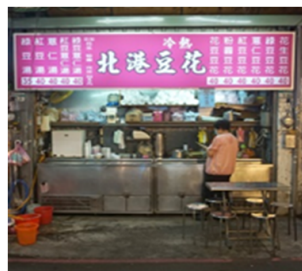

14 Tofu Pudding
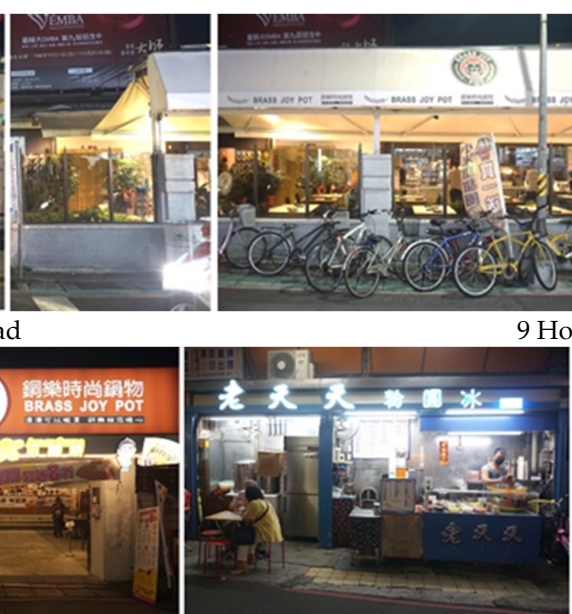

11 Shaved Ice

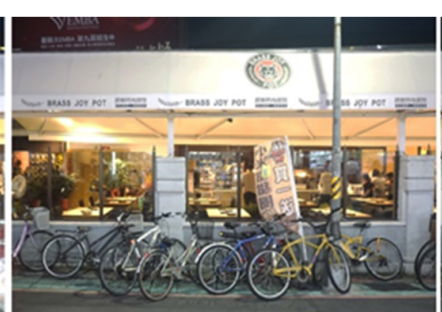

9 Hotpot along Lane 39, Shida Road

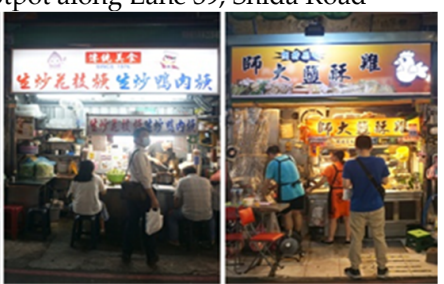

12 Squid and Duck

Stew

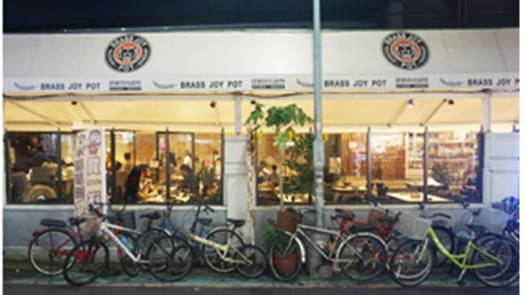

13 Fried Food

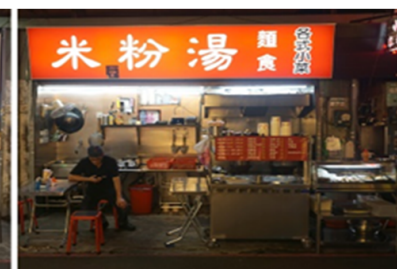

15 Noodle

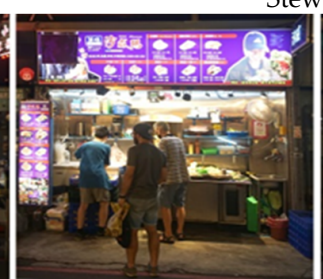

16 Shawarma

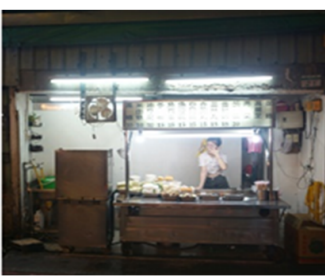

17 Luwei

(a)

Figure 4. Cont. 

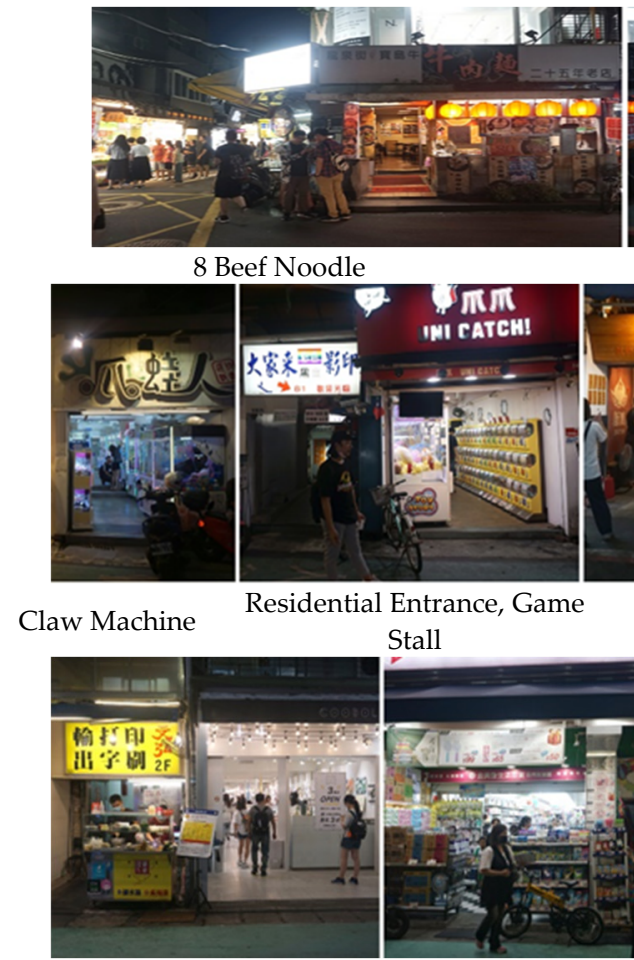

3 Salted Chicken

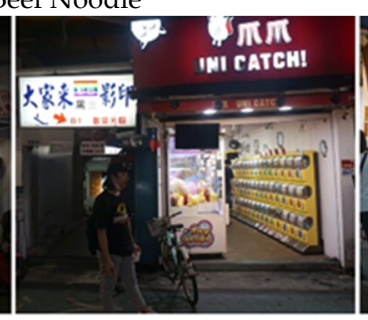

Stall

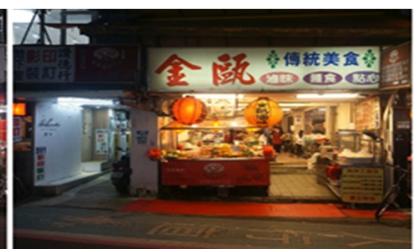

7 Luwei, Noodle, Dimsum

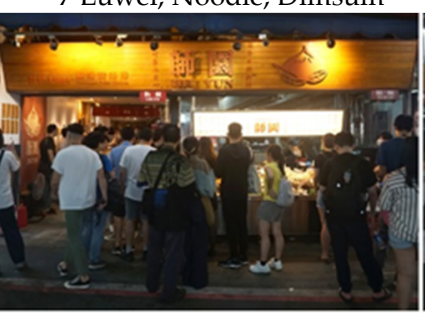

5 Fried food

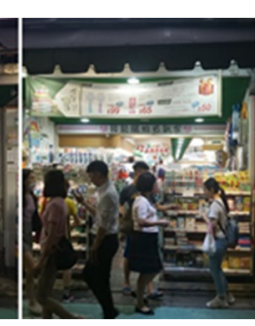

Appliance Store, Res.

Bookshop

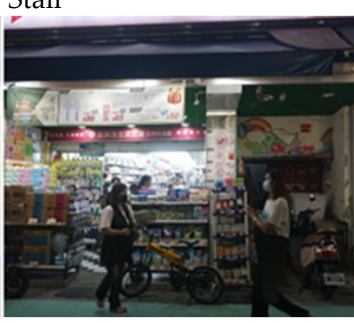

Entrance, Convenience

store

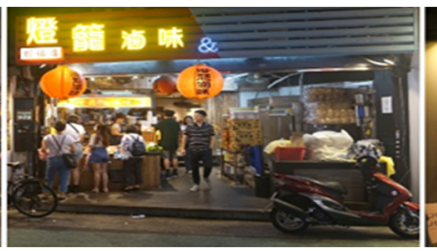

6 Luwei

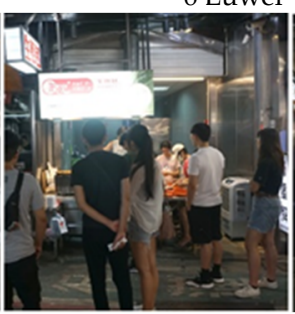

4 Dumpling

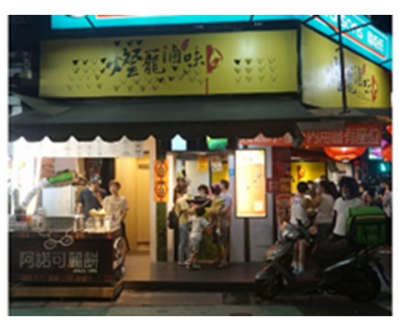

2 Crepe

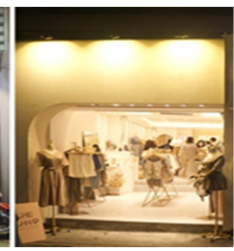

Clothes Shop

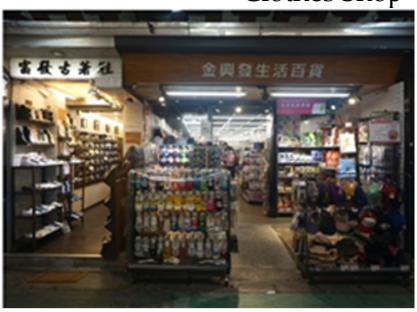

Shoe Stall, Convenience Store

(b)

Figure 4. (a) Elevation photos of shops 9 to 17 in Shida Night Market street segment A-N (photos by author). (b) Elevation photos of shops 1 to 8 in Shida Night Market street segment A-S (photos by author).

\section{Video Data Collection and Analysis Process}

To better understand pedestrian shopping behavior in segment $A$, video data were obtained on a weekend for a duration of $25 \mathrm{~min}$. Two time-lapse cameras were placed at both ends of the segment to capture images every two seconds. Time-lapse camera 1 was located in the park on the west side, camera 2 was located at the east end of the segment, and an additional 360-degree camera was placed in the middle of the segment to capture 25 min of video data to observe and follow the movement of the pedestrians thoroughly.

After all the information and data collection were conducted, the behavior of the pedestrians was mapped. This research is limited to the observation of pedestrians (or groups of pedestrians) entering from the west to east. Only pedestrians visiting food shops and pedestrians strolling along the segment are considered. The movement of the pedestrians walking through the segment was mapped, and the attraction (buying) and stopover locations were marked. The tracking of pedestrians ended if the pedestrian stayed in a shop for more than $5 \mathrm{~min}$ or if they reached the end of the segment. Five minutes is a common time interval in the pedestrian behavior survey [19]. In this study, an over $5 \mathrm{~min}$ stay in one food shop implies a "serious" eat and may change one's appetite. It would likely lead to the change of the attractiveness of other food shops. Such behaviors are beyond the scope of this study. The entry points of the observed pedestrians were noted, as well as the number of pedestrians coming from each point. The number of stops at each shop was also noted to determine the top-visited shops along the street segment. The collected data, including the total number of pedestrians and their corresponding entry points and top-visited shops (attraction factor), were then inputted into the simulation model for calibration. 


\subsubsection{Shida Night Market Street Segment A: Analysis and Results}

Based on the final field observation and video collection, there are seventeen possible visual attractors (food shops) in segment $\mathrm{A}$. The paths of pedestrians walking from the west end to the east end of the segment were observed and tracked, along with their attractions and stopovers.

A total of 149 pedestrians were tracked on a weekend night from 6:20 pm to $6: 45 \mathrm{pm}$ in April 2020. As recorded, 66 attracted pedestrians accounted for $44 \%$ of the total tracked pedestrians, and 83 strolling pedestrians accounted for the remainder. The percentage of pedestrians entering the three entry points was also recorded. The highest percentage of entry was on the west side, with 65 pedestrians $(44 \%)$. The south and north sides were relatively similar, with 44 and 40 pedestrians, respectively (Table 2). Attracted pedestrians are pedestrians who visited and purchased items from a shop, while strolling pedestrians are pedestrians who passed through the segment. Figure 5 shows the cumulative paths of tracked pedestrians along the street segment. Most pedestrians, both attracted and strolling, walk on the south side of the segment along shops 1 to 8 , with some diverting to the north due to high foot traffic in the middle of the segment. To improve understanding, the results of the behavior mapping are divided into two categories: attracted and strolling pedestrians.

Table 2. Percentage of attracted and strolling pedestrians and percentage of pedestrians per entry point.

\begin{tabular}{cccccc}
\hline & & & \multicolumn{3}{c}{ Entry Points } \\
\hline & Total Pedestrians & $\%$ & North Side & West Side & South Side \\
\hline Strolling & 83 & $56 \%$ & 20 & 39 & 24 \\
Attracted & 66 & $44 \%$ & 20 & 26 & 20 \\
Total & 149 & $100 \%$ & 40 & 65 & 44 \\
Percentage & & & $27 \%$ & $44 \%$ & $29 \%$ \\
\hline
\end{tabular}

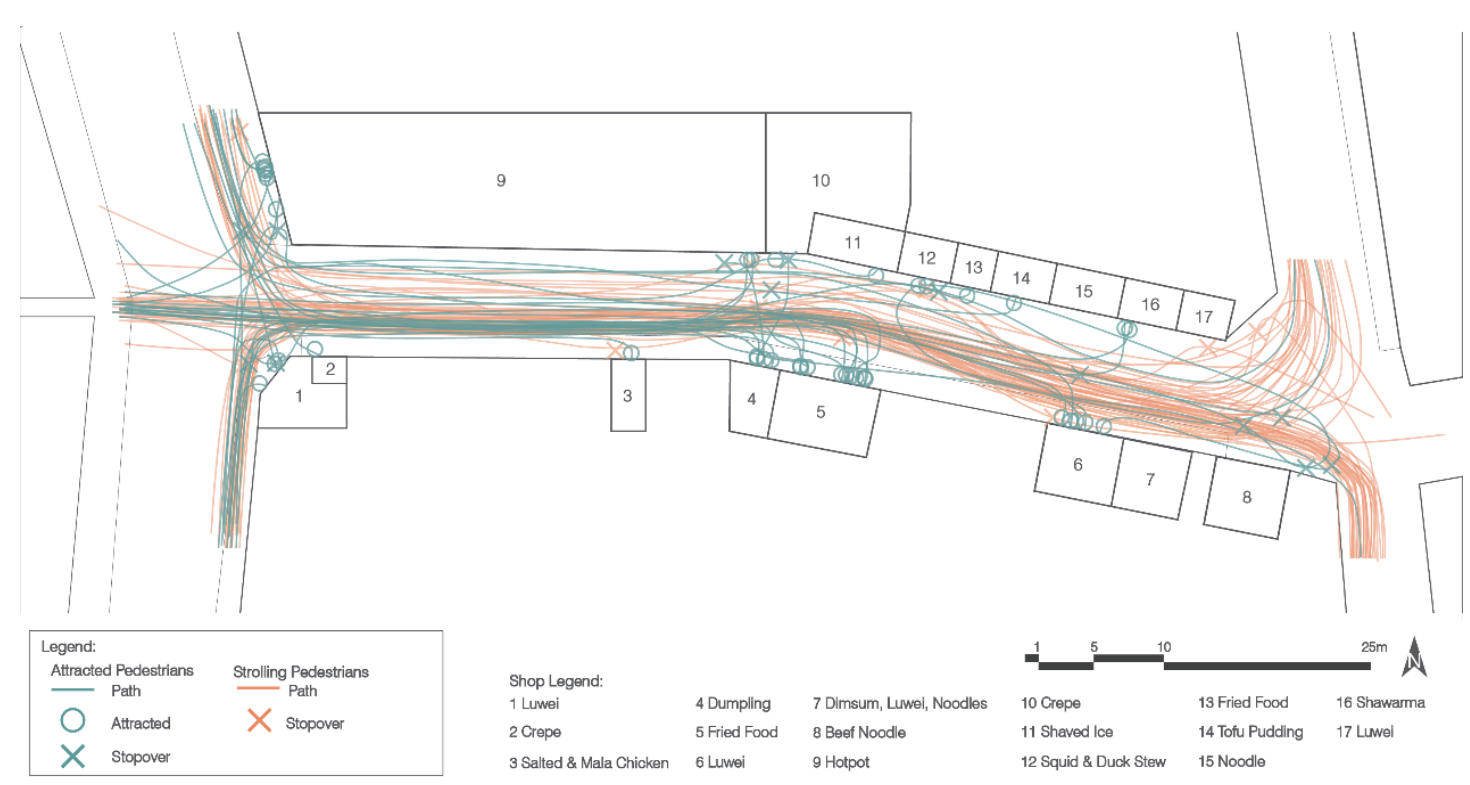

(a)

Figure 5. Cont. 


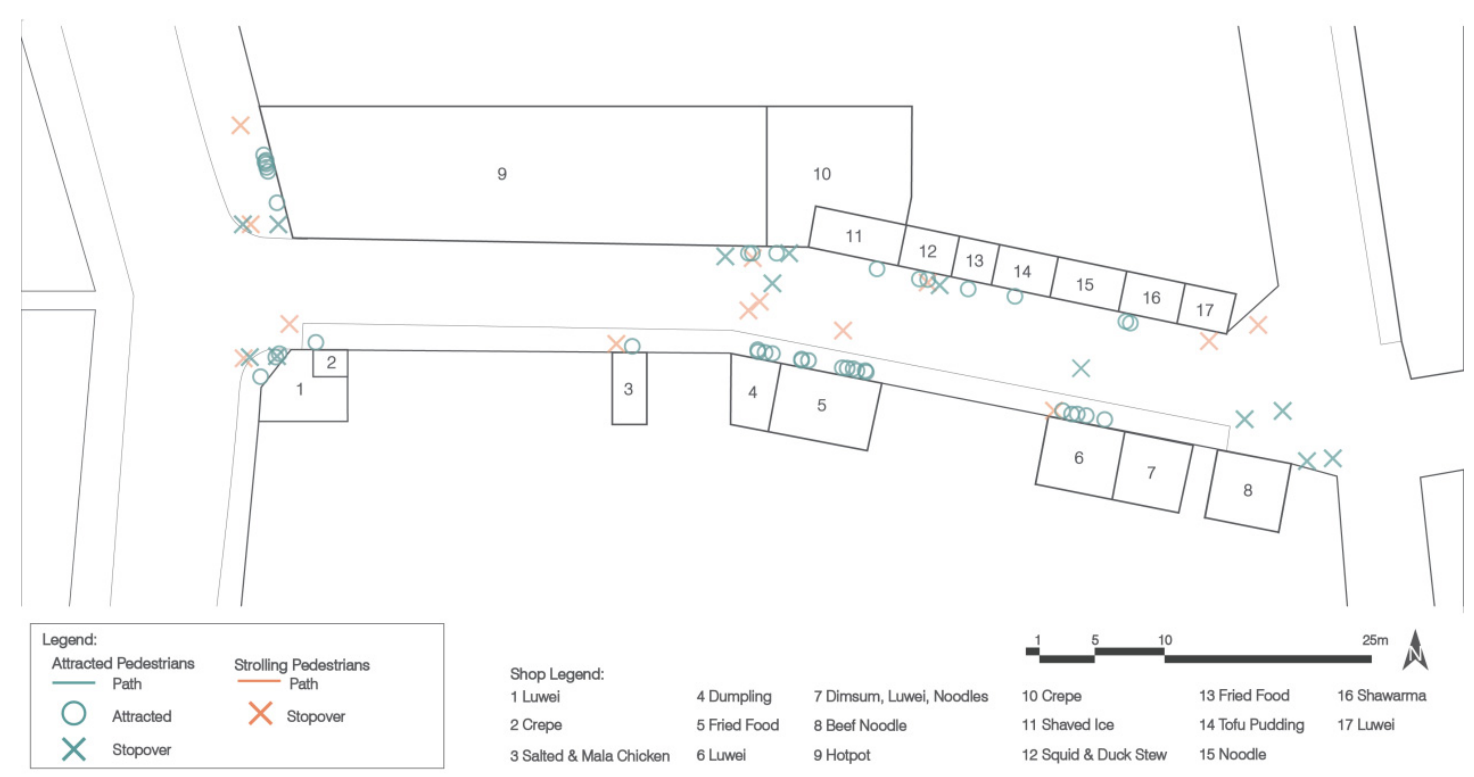

(b)

Figure 5. (a) Cumulative paths; (b) attraction and stopovers of attracted and strolling pedestrians.

\section{Strolling Pedestrians}

Pedestrians strolling along the street segment were accounted for. By observing and mapping their shopping behavior, these pedestrians can help in identifying which shops have the most stopovers and which part of the street segment attracts the most pedestrians. Figure 6 a shows the cumulative recorded paths of strolling pedestrians. Strolling pedestrians tend to walk along the south side (shops 1 to 8 ) but are occasionally diverted to the middle and north side due to pedestrians gathered near shops 4 and 5 , which sell dumplings and fried food, respectively. Then, pedestrians exit through either the northeast or southeast end of the segment.

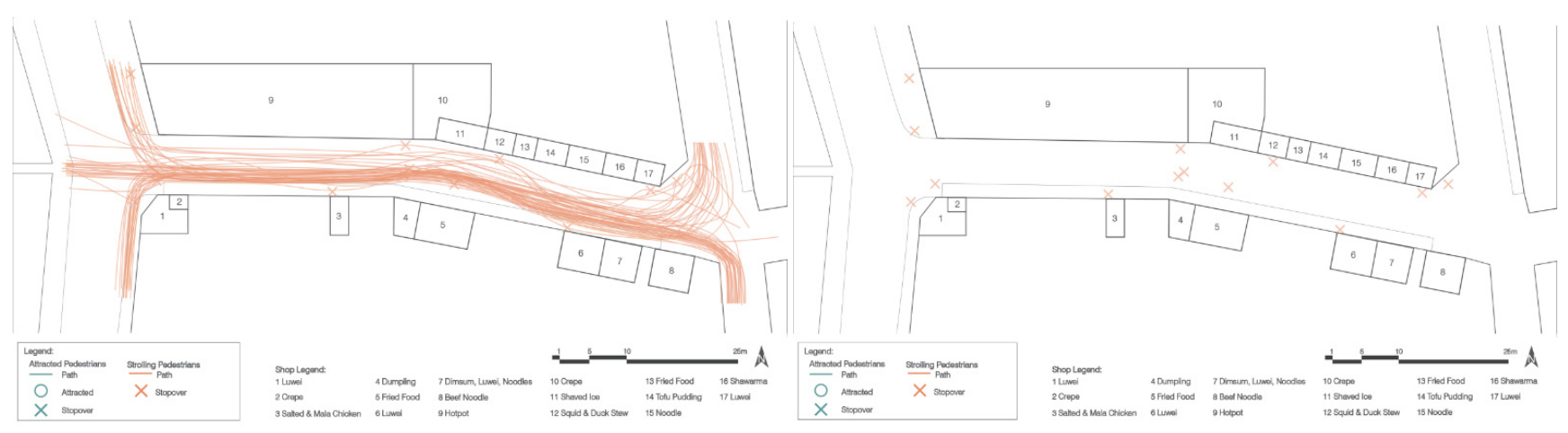

(a)

(b)

Figure 6. Cont. 


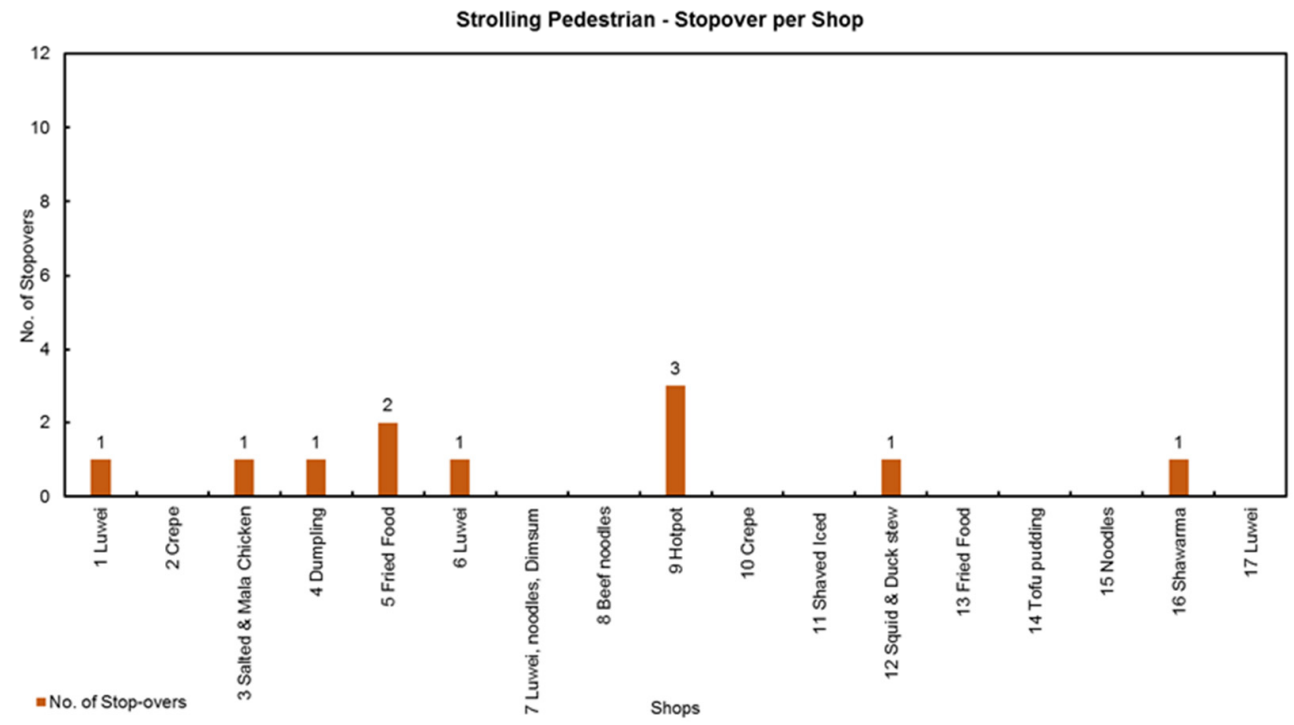

(c)

Figure 6. (a) Cumulative paths; (b) attraction and stopovers of strolling pedestrians; (c) strolling pedestrians per shop stopover.

Stopovers are more apparent in the middle of the street segment, mainly near shops 4 , 5 , and 10. Pedestrians may be attracted to the menu display of shop 10, while shops 4 and 5 have many pedestrians waiting for their food to be served. Some stopovers occur in the front of the section, such as at shops 1 and 9, which are both located at the entrance of the street segment. Pedestrians tend to wait and stop near these shops, resulting in a greater number of stopovers. Shop 9, a new hotpot restaurant, takes advantage of these stopovers by providing menu displays at the entrance. The back part of the segment had the fewest stopovers, with two stopovers near shop 17 (Figure $6 \mathrm{~b}, \mathrm{c}$ ).

\section{Attracted Pedestrians}

Attracted pedestrians are pedestrians who visited and purchased items at shops along the street segment. Pedestrians entered through all three possible entry points and followed paths mostly on the south side. The most consistent paths are near shops 1 to 5 (Figure 7a). Some pedestrians walk along the north side of the segment (shops 9-17) and visit a shop on the same side. The exit paths are not defined because many of the attracted pedestrians visit a shop and stop for more than $5 \mathrm{~min}$; therefore, their exit routes were not recorded.

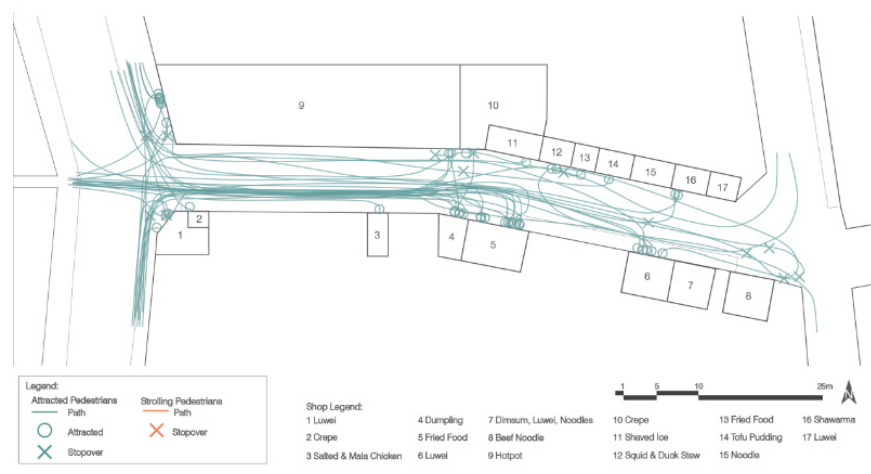

(a)

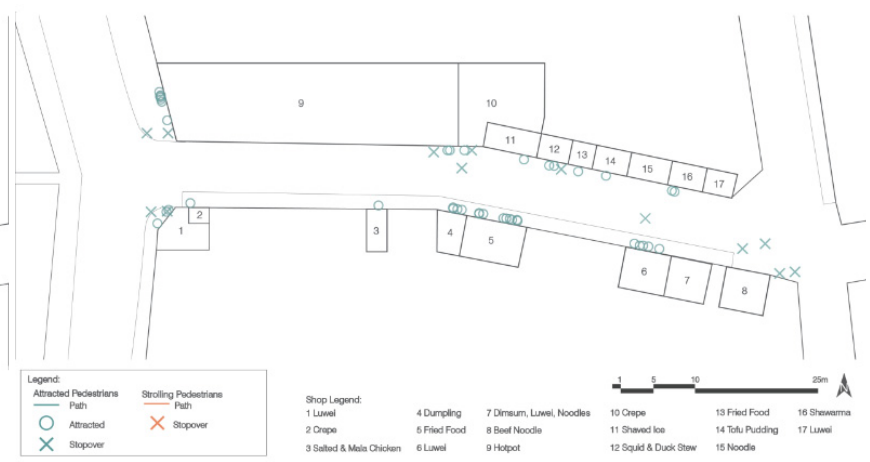

(b)

Figure 7. Cont. 


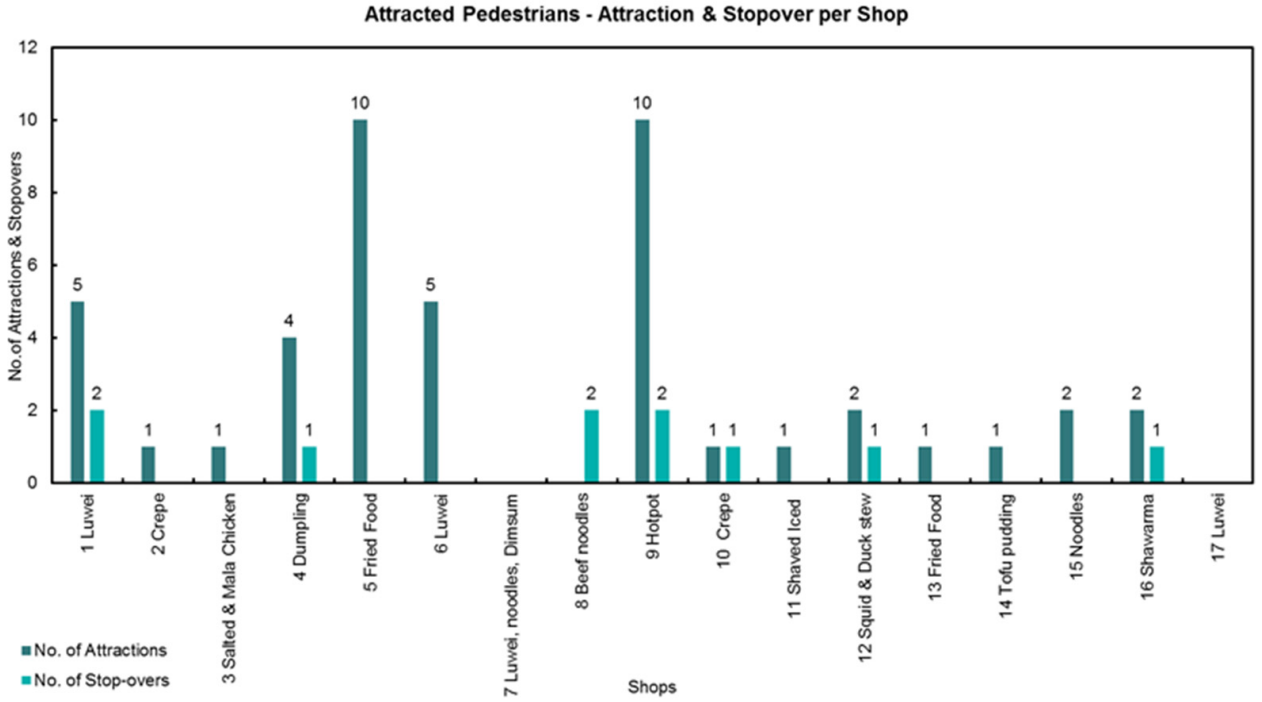

(c)

Figure 7. (a) Cumulative paths; (b) attraction and stopovers of attracted pedestrians; (c) attracted pedestrians per shop stopover.

The top five attractions are shops 1, 4, 5, 6, and 9, which are luwei, dumpling, fried food, luwei, and hotpot shops, respectively (Figure 7c) (Table 3). These shops are located in the front, middle, and back parts of the street segment, and the front and middle parts have higher attraction tendencies. Shops 7, 8, 15, and 17 had no attraction at all. Contrary to the number of attractions, the back part has the greatest number of stopovers, where pedestrians would stop for a while near shop 8 before deciding where to exit. The front part stopovers consist mainly of pedestrians waiting for companions to join them before entering the street segment. In the middle part, pedestrians tend to stop near shop 10, a relatively new shop, and shop 9, which also displays the shop's menu.

Table 3. Attracted pedestrian's shop attractions and stopovers (top 5 shops in bold).

\begin{tabular}{|c|c|c|c|c|c|c|}
\hline $\begin{array}{l}\text { No. of } \\
\text { Shops }\end{array}$ & Shop No. & Food Type & Location & $\begin{array}{c}\text { No. of } \\
\text { Attractions }\end{array}$ & $\begin{array}{c}\text { No. of } \\
\text { Stopovers }\end{array}$ & Total \\
\hline 1 & 9 & Hotpot & Front & 10 & 2 & 12 \\
\hline 2 & 5 & Fried Food & Middle & 10 & & 10 \\
\hline 3 & 1 & Luwei & Front & 5 & 2 & 7 \\
\hline 4 & 6 & Luwei & Back & 5 & & 5 \\
\hline 5 & 4 & Dumpling & Middle & 4 & 1 & 5 \\
\hline 6 & 12 & Squid and Duck stew & Middle & 2 & 1 & 3 \\
\hline 7 & 16 & Shawarma & Back & 2 & & 2 \\
\hline 8 & 10 & Crepe & Middle & 1 & 1 & 2 \\
\hline 9 & 2 & Crepe & Front & 1 & & 1 \\
\hline 10 & 3 & Salted and Mala Chicken & Front & 1 & & 1 \\
\hline 11 & 11 & Shaved Iced & Middle & 1 & & 1 \\
\hline 12 & 13 & Fried Food & Back & 1 & & 1 \\
\hline 13 & 14 & Tofu Pudding & Back & 1 & & 1 \\
\hline 14 & 8 & Beef Noodles & Back & & 4 & 4 \\
\hline 15 & 7 & Luwei, Noodles, Dimsum & Back & & & 0 \\
\hline 16 & 15 & Noodles & Back & & & 0 \\
\hline \multirow[t]{2}{*}{17} & 17 & Luwei & Back & & & 0 \\
\hline & & Total & & 44 & 11 & 55 \\
\hline
\end{tabular}


The back part has the greatest number of shops per location; however, it had the fewest attractions, even though shop 6 (luwei) is one of the top shops. The front and middle shops had more top options, including hotpot, luwei, dumpling, and fried food shops. Although the front and middle areas had fewer shops, 4 and 5 shops, respectively, these shops had more attractions and stopovers (Table 3). This tendency was also observed with regard to the overall attractions per location: the middle shops had the most attractions, with 18 visits (40.91\%), followed closely by the front shops, with 17 visits $(38.64 \%)$, while the back shops had the fewest attractions, with 9 visits $(20.45 \%)$, as shown in Table 4 . This result may be due to differences in food type, location, and proximity to top shops. The front and middle areas each had two top shops; these top shops help boost the attraction of nearby shops.

Table 4. Attracted pedestrian's shop attractions and stopovers count and percentage.

\begin{tabular}{cccc}
\hline Location & No. of Shops & No. of Attractions & $\%$ \\
\hline Front & 4 & 17 & $38.64 \%$ \\
Middle & 5 & 18 & $40.91 \%$ \\
Back & 8 & 9 & $20.45 \%$ \\
Total & 17 & 44 & $100.00 \%$ \\
\hline
\end{tabular}

The data collected along the Shida Night Market street segment, such as the total number of pedestrians tracked (both attracted and strolling pedestrians), strolling tendencies, percentages per entry point, number of attractions per shop and per location, and percentages of attractions per location, were applied in the simulation model for calibration and validation.

\subsection{Simulation Model: NetLogo 5.2.0}

NetLogo is open-source microscopic agent-based modeling software that can visualize and mobilize agents over a grid environment. Agents (turtles) can explore independently, connect with other agents at a microscopic level, and interact with macrolevel patterns. The environment is a grid divided into cells, which are referred to as patches [20]. The basic concept of agent-based modeling (ABM) is self-governing agents (turtles) that interact in a common environment, also known as individual-based models (IBMs). These agents act individually and have their own individual internal properties. The behavior of an agent can be depicted as a state-determined automata (finite state machine), and a state transition may occur when the agent interacts with another agent [21]. This simple behavior rule generates complex behavior. This software will aid research in simulating pedestrian shopping behavior by formulating a visual attraction model.

After the initial observation, data collection, and analysis were conducted, the data were applied to the simulation along with the theory of natural movement. This concept considers the configuration as the primary generator of pedestrian movement patterns, and attractors generally work to strengthen the fundamental pattern created by configuration. The presence of attractors can affect movement but cannot change the fixed spatial layout of a space. Likewise, the locations of attractors cannot influence the configuration [11]. This theory takes shops as attractors, the night market segment layout as the configuration, and pedestrian shopping behavior as movement (Figure 8). Moreover, the pedestrian's individual visual attention range is considered when selecting a destination [16]. 


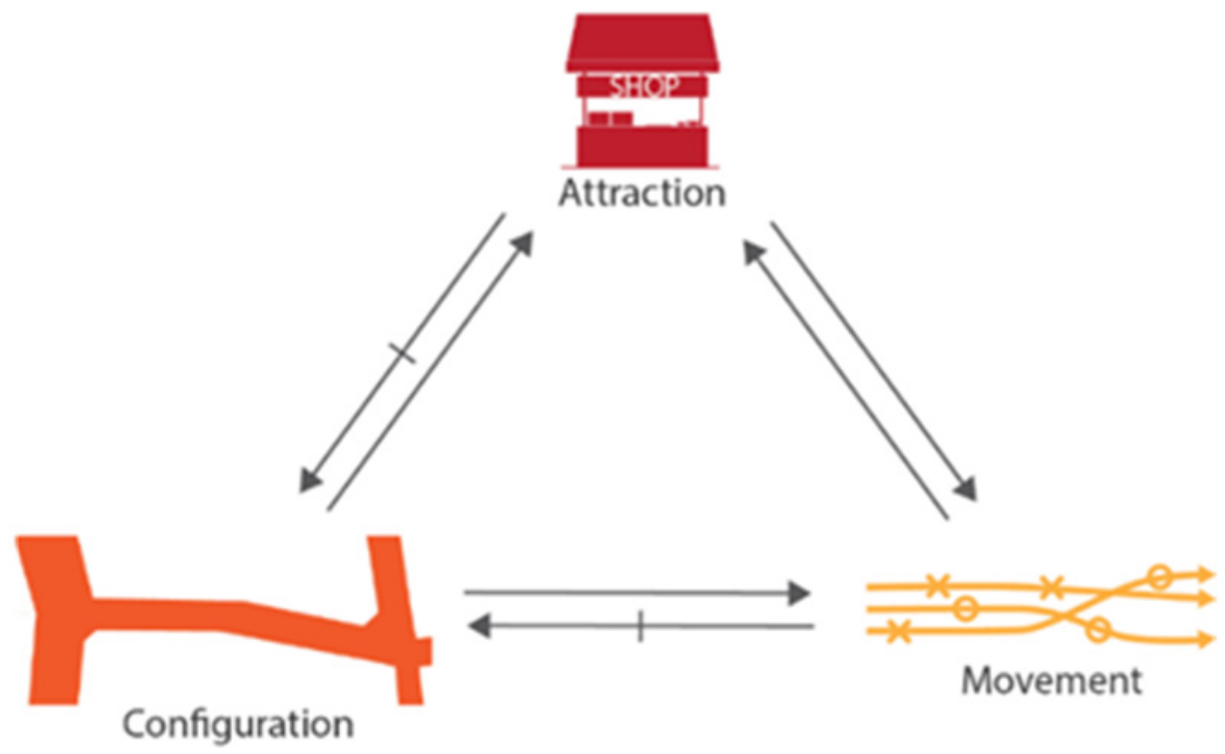

Figure 8. Theory of natural movement [11] applied to the research: shops as attraction; night market layout as configuration; pedestrian's shopping behavior as movement.

The simulation model input data includes the pedestrian's visual attraction navigation parameters and the environment parameter, which yield the visual attraction model. The simulation model is calibrated and validated with the final observation and data collection results to assess whether the simulation accurately reflects pedestrian behavior in the Shida Night Market street segment.

\subsubsection{Environment Parameters}

NetLogo's grid environment is composed of cells that are referred to as patches. For this research, each patch size was approximately $75 \mathrm{~cm} \times 75 \mathrm{~cm}$, where the value was derived from the average step length of mature humans-approximately $0.77 \mathrm{~m}[12,22]$. Through this setting, the data collection of the layout of the Shida Night Market street segment is applied to the simulation model. Figure 9 shows the software interface.

The implementation of the street segment layout produced a test space of approximately $141 \times 61$ patches, with a total of 17 shops identified in the street segment. Shops are divided into three parts: front, middle, and back, which are assigned red, blue, and orange colors, respectively. Shops are also numbered for easy identification. Entry point patches are assigned on the left side of the test space, and exit patches are on the right.

Attraction factors, such as attraction level and radius of influence, are introduced to attract agents to a particular shop. The attraction level refers to the amount of patch influence a shop has. The radius of influence represents the distance of the attraction. Therefore, the higher the attraction factors are, the more likely it is that agents will visit the shop (Figure 10). Moreover, the identification of hotspots may help in determining the effects of these most visited shops on nearby stores [17]. 


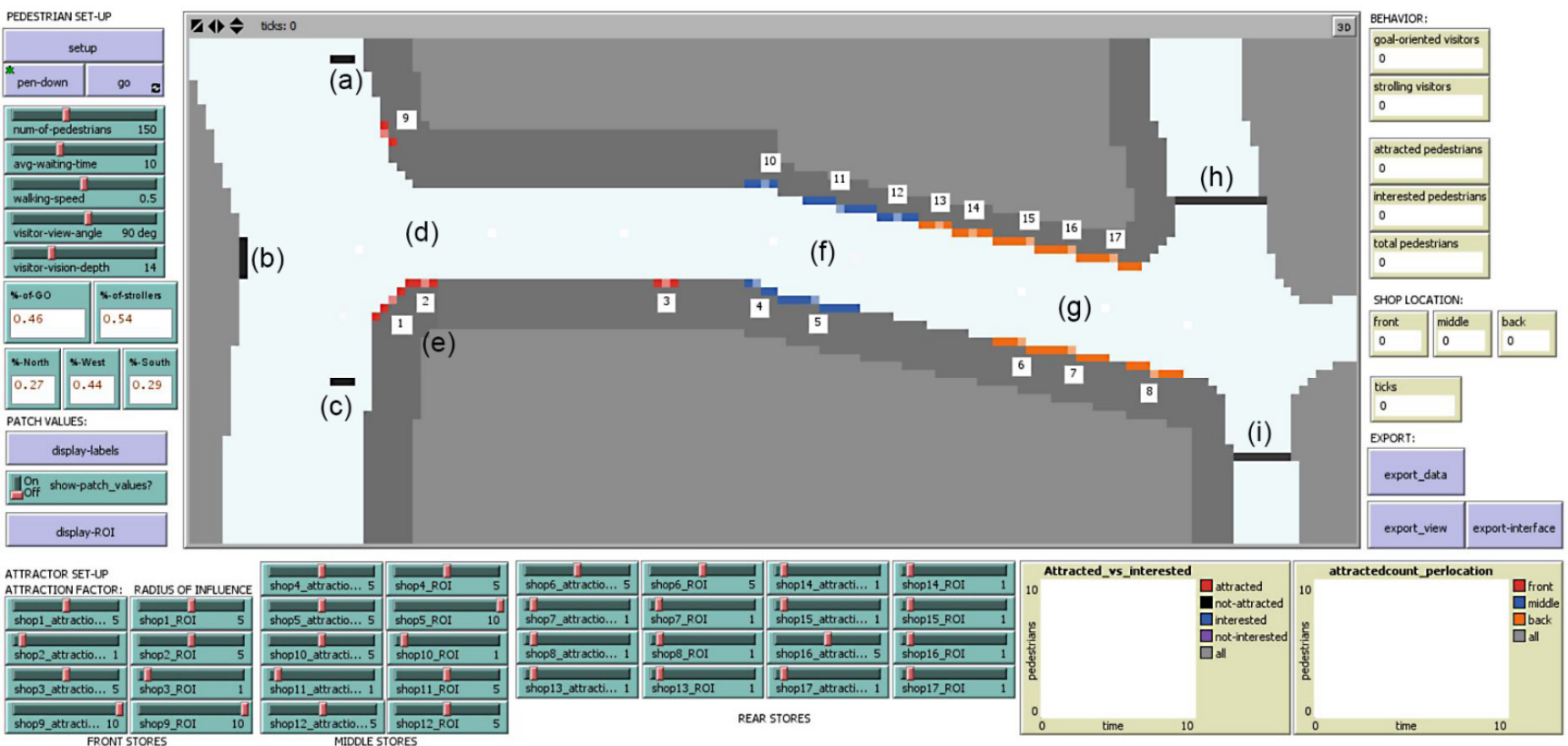

Figure 9. NetLogo interface of the visual attraction simulation model with the Shida Night Market street segment layout. Entry points: (a) north side, (b) west side, (c) south side; (e) shop number; Shopsshops: (d) front, (f) middle, (g) back shops; Exit; exit patches: (h) north exit patches, (i) south exit patches. The numbers in the square boxes are the shop numbers.

Table 5. Simulation parameters and values.

\begin{tabular}{|c|c|c|c|c|}
\hline Agent's Configuration Profile & Values & $\begin{array}{l}\text { Simulated } \\
\text { Values }\end{array}$ & Unit & Description \\
\hline No. of Pedestrians & 1 to 400 & 150 & agents & $\begin{array}{l}\text { total number of agents to be released in } \\
\text { the environment }\end{array}$ \\
\hline Average waiting time & 1 to 30 & 10 & ticks & $\begin{array}{l}\text { waiting time/ticks when agent stops at the } \\
\text { counter patches }\end{array}$ \\
\hline Walking Speed & $0.5,1.0$ & 0.5 & patch & $\begin{array}{l}\text { agent's speed of walking when going } \\
\text { through the environment }\end{array}$ \\
\hline Visitor view angle & 1 to 170 & $90,120,150$ & degrees & $\begin{array}{l}\text { agent's view angle when evaluating a } \\
\text { current and new target patch }\end{array}$ \\
\hline Visitor Vision Depth & $14,26,40$ & $14,26,40$ & patches & $\begin{array}{l}\text { agent's vision depth when evaluating a } \\
\text { current and new target patch }\end{array}$ \\
\hline $\begin{array}{c}\text { Pedestrian Percentage per } \\
\text { Visitor Type }\end{array}$ & $\%$ & Simulated \% & Unit & Description \\
\hline$\%$ of Goal-Oriented Visitors & 0-99 & 46 & $\%$ & $\begin{array}{l}\text { agents with a predetermined destination } \\
\text { (dest-patch) }\end{array}$ \\
\hline$\%$ of Strolling Visitors & 0-99 & 54 & $\%$ & $\begin{array}{l}\text { walking agents with no } \\
\text { predetermined destination }\end{array}$ \\
\hline $\begin{array}{c}\text { Percentage of Visitors per } \\
\text { Entry Point }\end{array}$ & $\%$ & Simulated \% & Unit & Description \\
\hline North Side & 0-99 & 27 & $\%$ & $\begin{array}{l}\text { agents coming from the north when } \\
\text { entering the segment }\end{array}$ \\
\hline West Side & 0-99 & 44 & $\%$ & agents coming from the west \\
\hline South Side & 0-99 & 29 & $\%$ & agents coming from the south \\
\hline
\end{tabular}


Table 5. Cont.

\begin{tabular}{|c|c|c|c|c|}
\hline Shop Attraction Factor & Values & $\begin{array}{l}\text { Simulated } \\
\text { Values }\end{array}$ & Unit & Description \\
\hline \multicolumn{5}{|l|}{ Front (red) } \\
\hline Shop 1 & & & & \multirow{3}{*}{$\begin{array}{l}\text { amount of patch influence of a shop } \\
\text { extension of the amount of influence of } \\
\text { a shop }\end{array}$} \\
\hline Attraction Level & $1,5,10$ & 5 & patches & \\
\hline Radius of Influence & $1,5,10$ & 5 & patches & \\
\hline \multicolumn{5}{|r|}{ a situp } \\
\hline Attraction Level & $1,5,10$ & 1 & patches & \\
\hline \multicolumn{5}{|l|}{ Shop 3} \\
\hline Attraction Level & $1,5,10$ & 5 & patches & \\
\hline \multicolumn{5}{|l|}{ Shop 9} \\
\hline Attraction Level & $1,5,10$ & 10 & patches & \\
\hline Radius of Influence & $1,5,10$ & 10 & patches & \\
\hline \multicolumn{5}{|l|}{ Middle (blue) } \\
\hline \multicolumn{5}{|l|}{ Shops 4,12} \\
\hline Attraction Level & $1,5,10$ & 5 & patches & \\
\hline \multicolumn{5}{|l|}{ Shop 5} \\
\hline Attraction Level & $1,5,10$ & 5 & patches & \\
\hline \multicolumn{5}{|l|}{ Shop 10} \\
\hline Attraction Level & $1,5,10$ & 5 & patches & \\
\hline \multicolumn{5}{|l|}{ Shop 11} \\
\hline Attraction Level & $1,5,10$ & 1 & patches & \\
\hline Radius of Influence & $1,5,10$ & 5 & patches & \\
\hline \multicolumn{5}{|l|}{ Back (orange) } \\
\hline \multicolumn{5}{|l|}{ Shop 6} \\
\hline Attraction Level & $1,5,10$ & 5 & patches & \\
\hline Radius of Influence & $1,5,10$ & 5 & patches & \\
\hline \multicolumn{5}{|l|}{ Shops $7,8,13,14,15,17$} \\
\hline Attraction Level & $1,5,10$ & 1 & patches & \\
\hline $\begin{array}{l}\text { Radius of Influence } \\
\text { Shop } 16\end{array}$ & $1,5,10$ & 1 & patches & \\
\hline Attraction Level & $1,5,10$ & 5 & patches & \\
\hline Radius of Influence & $1,5,10$ & 1 & patches & \\
\hline
\end{tabular}

As agents pass through the patches in the environment, the patch influence increases. The patch influence for each patch is initially set to a default value of 1 , and this parameter indicates where agents have passed and the overall visitation frequency of a patch. A sample occupancy heat map is shown in Figure 11. 


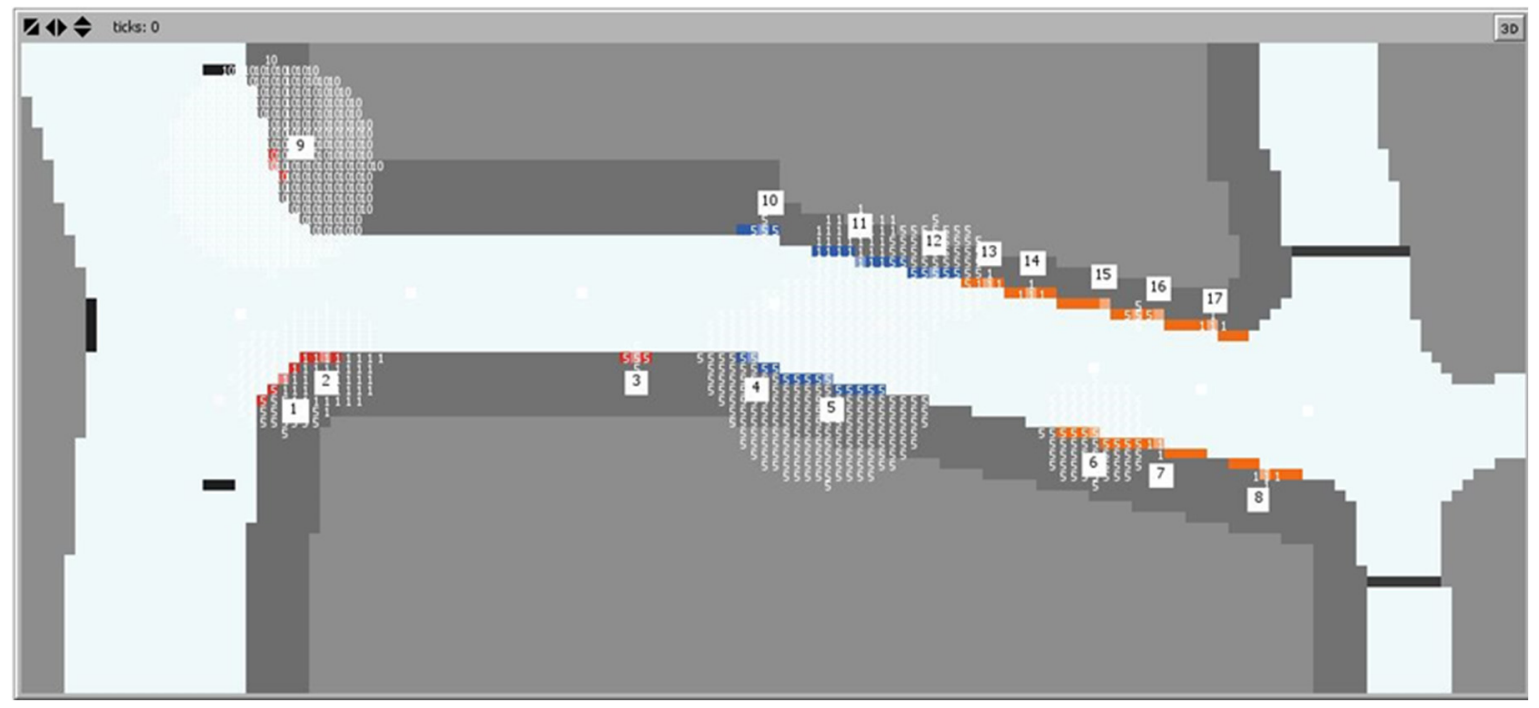

Figure 10. NetLogo Shop attraction level and radius of influence application to the simulation model (see Table 5 for full details on the parameter setting). The numbers in the square boxes are the shop numbers.

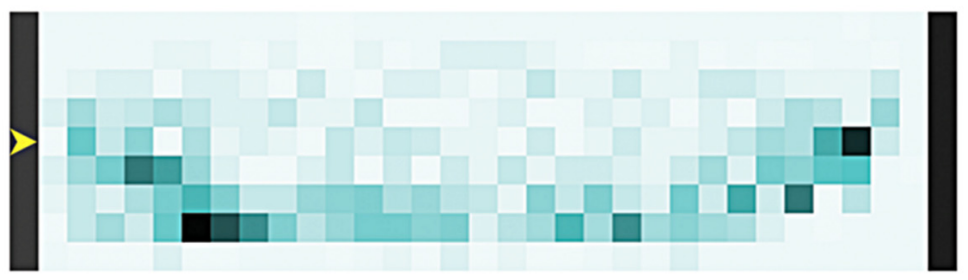

scale bar

less

more occupancy

Figure 11. NetLogo patch occupancy heat map.

\subsubsection{Pedestrians' Visual Attraction Navigation Parameters}

Goal-directed and exploratory behavior is observed in pedestrian movement when navigating through a complex environment [23]. The desire to move to a specific location is referred to as goal-oriented behavior. Exploratory behavior is prompted by detecting objects in a path that are visually attractive when traveling toward a goal destination. This behavior affects the agent's destination selection with respect to internal demands (pedestrian) and external factors (shops).

Pedestrian exploratory behavior has four stages: (1) strolling, walking along a path to the final goal (when no attractors are identified); (2) evaluating, checking if any attractors are within the visitor's view angle and depth choosing the nearest attractor and the one with the greatest patch influence value; (3) attracting and visiting, switching to the new goal and stopping for a brief time; (4) re-evaluating, pedestrians rechecking whether additional attractors remain after being attracted to and stopping at an attraction. After proceeding through all four stages, the agent will exit the environment (Figure 12). 


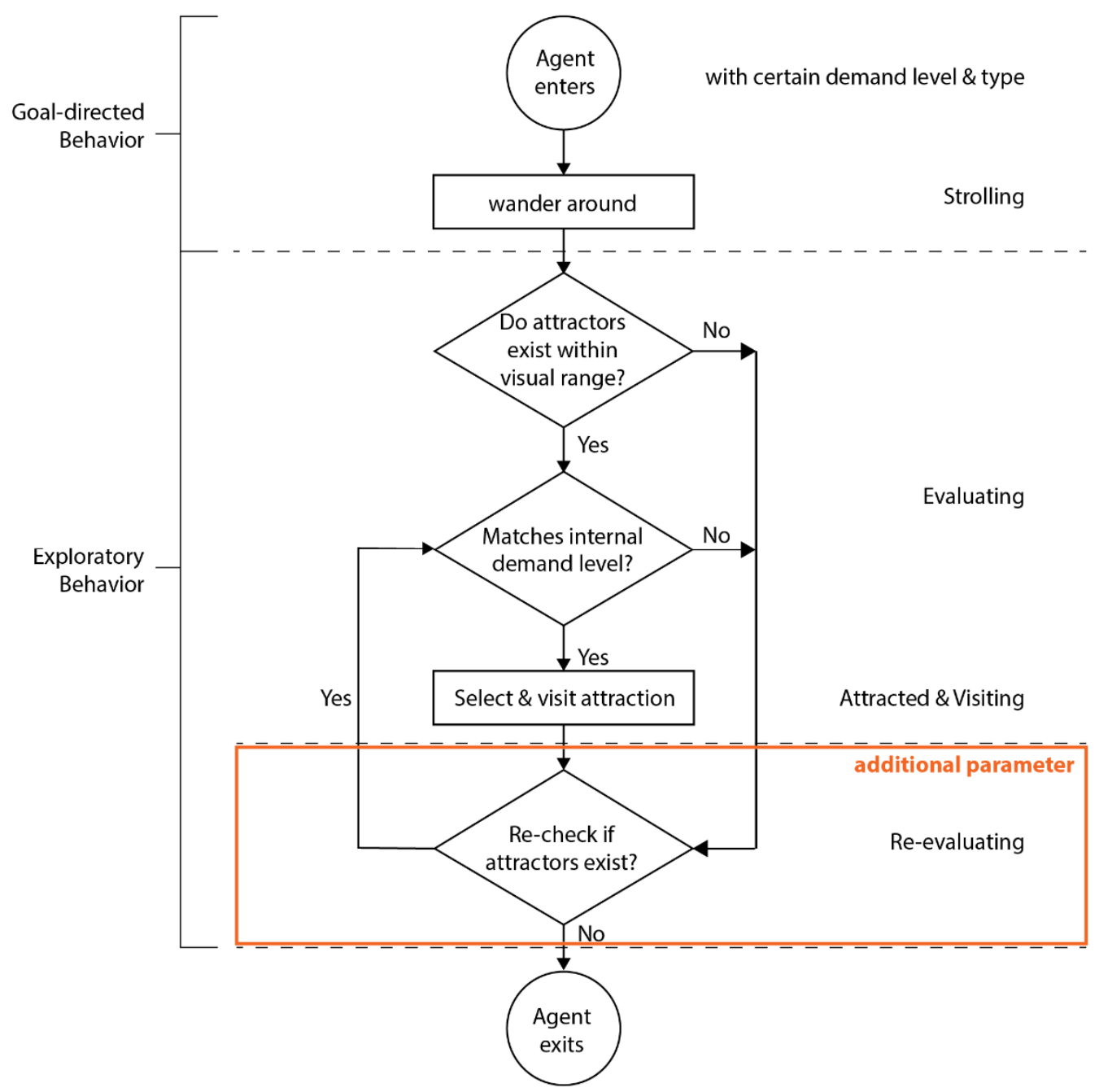

Figure 12. Agent's visual attraction movement process derived from [16] and the added "re-evaluating" parameter for this research (drawn by author).

\section{Strolling Behavior}

The strolling parameters are set such that the agent enters from any of the three entry points identified in the final observation and data collection steps. These entry points are north, west, and south on the west end of the street segment. Then, the agent passes through the segment and eventually reaches the end, exiting at the northeast or southeast end of the segment, according to the exit point set upon entering the environment.

When entering the environment, the agent is already set to have a particular demand level, demand type, and exit patch. The demand level refers to the agent's (pedestrian's) internal demand level, which takes values of 0 or 1 , where 0 indicates visitor agents with no predetermined destination. These agents are not attracted to any of the attractions in the environment. A value of 1 indicates visitor agents that have a shop as their predetermined destination, which is then divided in four demand types with a value range from 0 to 3: 0 is when the agent's predetermined destination (dest-patch) is one of the shops in the front part of the street segment; 1 refers to the shops at the middle; 2 are the shops at the end; 3 refers to the agents with demand levels of 0 , with no predetermined destination. An exit patch is also assigned to each agent upon entering and serves as the exit point (Figure 13). 


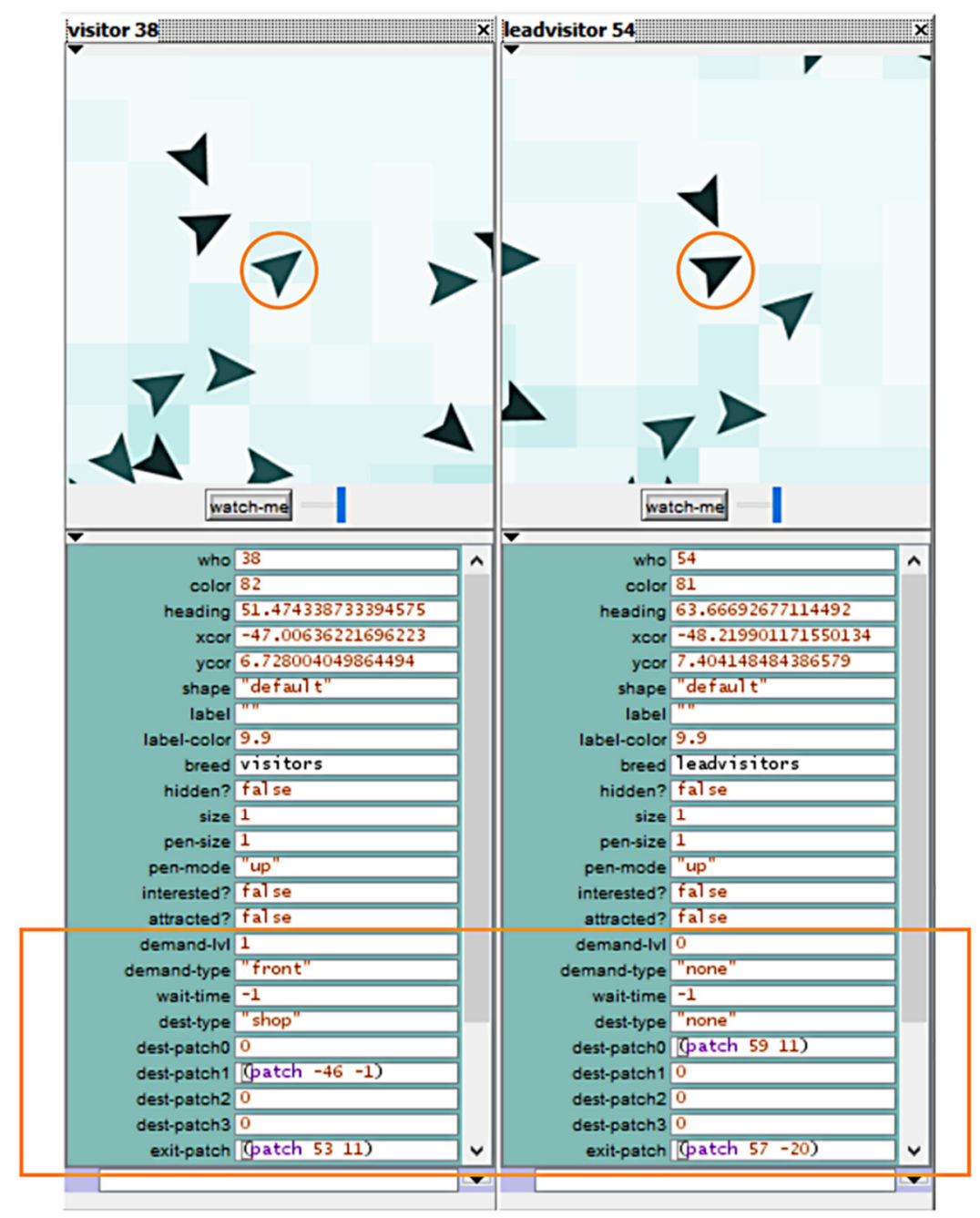

Figure 13. NetLogo Agent monitors showing its predefined parameters.

2. Attraction Behavior, Vision Angle, and Depth

The attraction parameters are referred during the evaluation stage, where the agent checks if the patches within the visual attraction range match the internal demand and have the highest patch influence. This parameter determines if the agent goes to the predetermined destination patch (dest-patch) or a new target patch. When the agent is attracted to a different patch, the agent remains for a short period that depends on value of the "waiting time" slider in the interface, which is incremented by 1 for attraction visit (Figure $14 \mathrm{a}-\mathrm{d}$ ). 


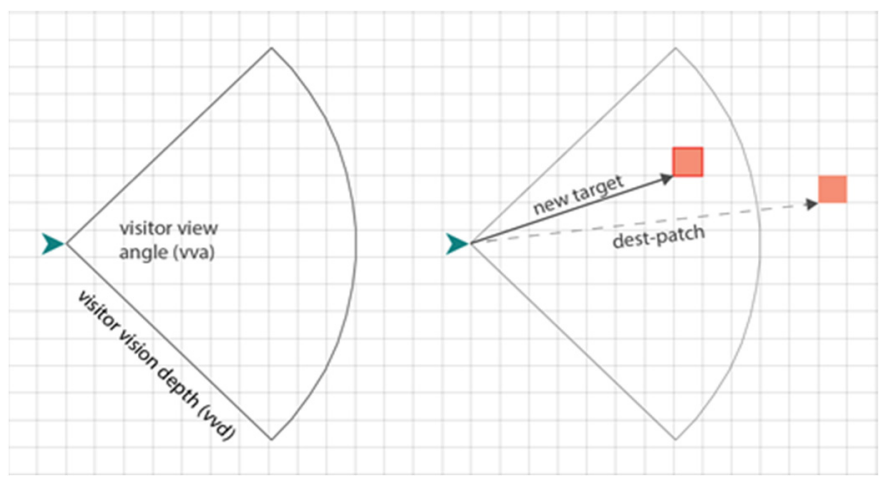

(a)

(b)

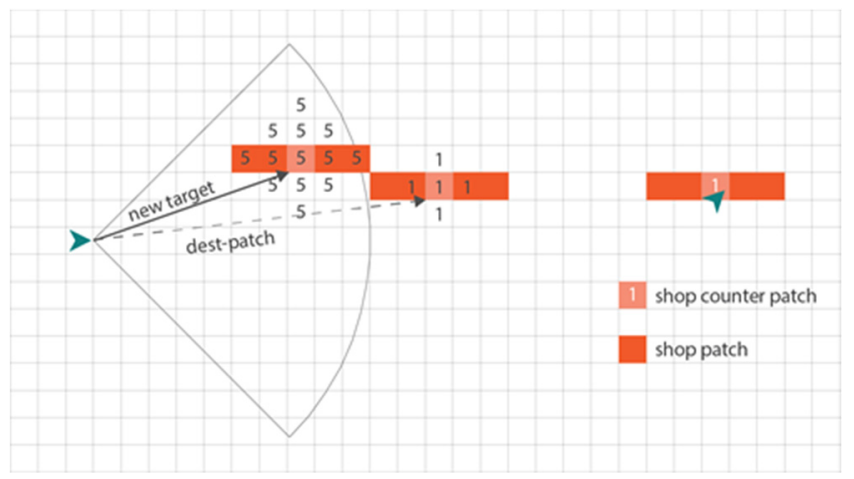

(c)

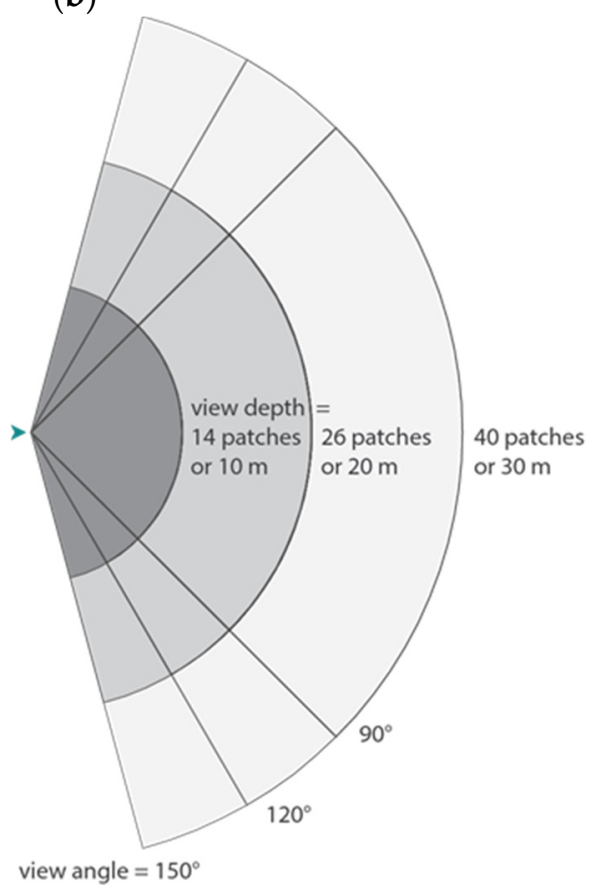

(e)

Figure 14. Evaluating, visiting, and attracted stages: (a) visual attraction range of the agent; (b) evaluating stage; (c) agent checking which patch to go; (d) agent being attracted and stopping at the shop with visit count reflected on shop counter patch; (e) visual attraction ranges to be tested in the model using $90^{\circ}, 120^{\circ}$, and $150^{\circ}$ angles and 14,26 , and 40 patches (10, 20 , and $30 \mathrm{~m}$; respectively) (illustrated by author).

To identify a current and new target, the agent needs to check for any possible attractors within the visual attraction range: visitor view angle (vva) and visitor view depth (vvd). The visitor view angle is simulated based on the $170^{\circ}$ vision angle of the pedestrian's field of view in a gallery, and different view angles $\left(90^{\circ}, 120^{\circ}\right.$, and $\left.150^{\circ}\right)$ are used to check the attention range of pedestrians in a shopping scenario [12,16]. Three visitor view depths $(10 \mathrm{~m}, 20 \mathrm{~m}$, and $30 \mathrm{~m})$ are simulated to identify the visual attraction range in the night market street segment.

In addition to the predefined destination (dest-patch) assigned to the agent upon entering the environment, the current destination is selected based on attractors within the visitor's visual attraction range. The agent will identify if the demand to visit a new attraction is the same or even greater than that to visit the initial destination; then, the agent will choose a new temporary destination or proceed to the predefined designation. As the agent travels to the destination, a shop counter patch counts the number of visits to that particular shop (Figure 14a-d). 
Figure $14 \mathrm{e}$ shows the attraction ranges tested in the simulation model. By testing these simulation groups, the simulation model can be calibrated and validated, and the visual attraction range of pedestrians in Shida Night Market street segment A can be determined.

\subsubsection{Visual Attraction Model: Parameter Settings}

Table 5 shows the parameter settings used in the simulation model. These settings can be adjusted to calibrate the simulation model based on observed data; therefore, the accuracy of the model can be validated and verified.

The model is divided into four main categories: (1) the agent's configuration profile can be used to adjust each agent's (visitor's) parameters, including the number of pedestrians in the environment, their average waiting time in a shop, walking speed, visitor view angle, and visitor depth; (2) pedestrian percentage of visitor type, which can be used to adjust the input percentage of goal-oriented and strolling visitors; (3) the percentage of visitors per entry point, which represents the percentages of visitors coming from the north, west, and south side entry points; (4) the shop attraction factor, which is composed of the attraction level and radius of influence of each shop.

The simulated values of the attraction level and radius of influence for each shop were based on the observed data regarding the visits and stopovers for each shop. Values of 1, 5, and 10 are possible. The attraction level was based on the number of visits to each shop, while the radius of influence (ROI) depended on the number of stopovers at or near the shop. The length of time that a shop has been open is also considered for the ROI, where the newer a shop is, the greater its radius of influence, resulting in agents (visitors) being more likely to visit that shop. For instance, shop 9 had values of 10 for both attraction level and radius of influence because it is a relatively new shop in the segment and received many visits.

\section{Results and Comparisons}

\subsection{Simulation Results}

The calibration of the simulation model with the field-observed data depicts the number of attractions per shop with regard to the pedestrian's visual attraction range, the shop's attraction level, and radius of influence. This was accomplished by simulating different groups, as shown in Table 6. Figure 15 shows a representation of different visitor view angles (vva) and visitor vision depths (vvd) as the agent walks through the simulation environment. A total of 30 simulations were performed for each simulation subgroup, where each subgroup had a different visitor view angle and visitor vision depth. The percentages of visitor types and visitor per entry points from the observed data were inputted into the simulation model. Prior to the final simulations, eight test simulation groups were considered to identify the attraction factors: attraction level, and radius of influence of each shop. These test simulations had varying specified attraction factors and were used to re-examine the results from the observed data. Applying the results from the observed data regarding the top attractors (shops) is vital in the configuration of the attraction factor parameters. The identification of the top shops, such as shops 1 and 9 (front), shops 4 and 5 (middle), and shop 6 (back), was considered when setting the parameters for the attraction level and radius of influence. Table 6 displays a detailed list of the simulation parameters. 
Table 6. Simulation groups for checking the visual attraction range in the street segment.

\begin{tabular}{cccc}
\hline Simulation Groups & a & b & c \\
\hline SG1 & vva90 vvd14 & vva120 vvd14 & vva150 vvd14 \\
SG2 & vva90 vvd26 & vva120 vvd26 & vva150 vvd26 \\
SG3 & vva90 vvd40 & vva120 vvd40 & vva150 vvd40 \\
\hline
\end{tabular}

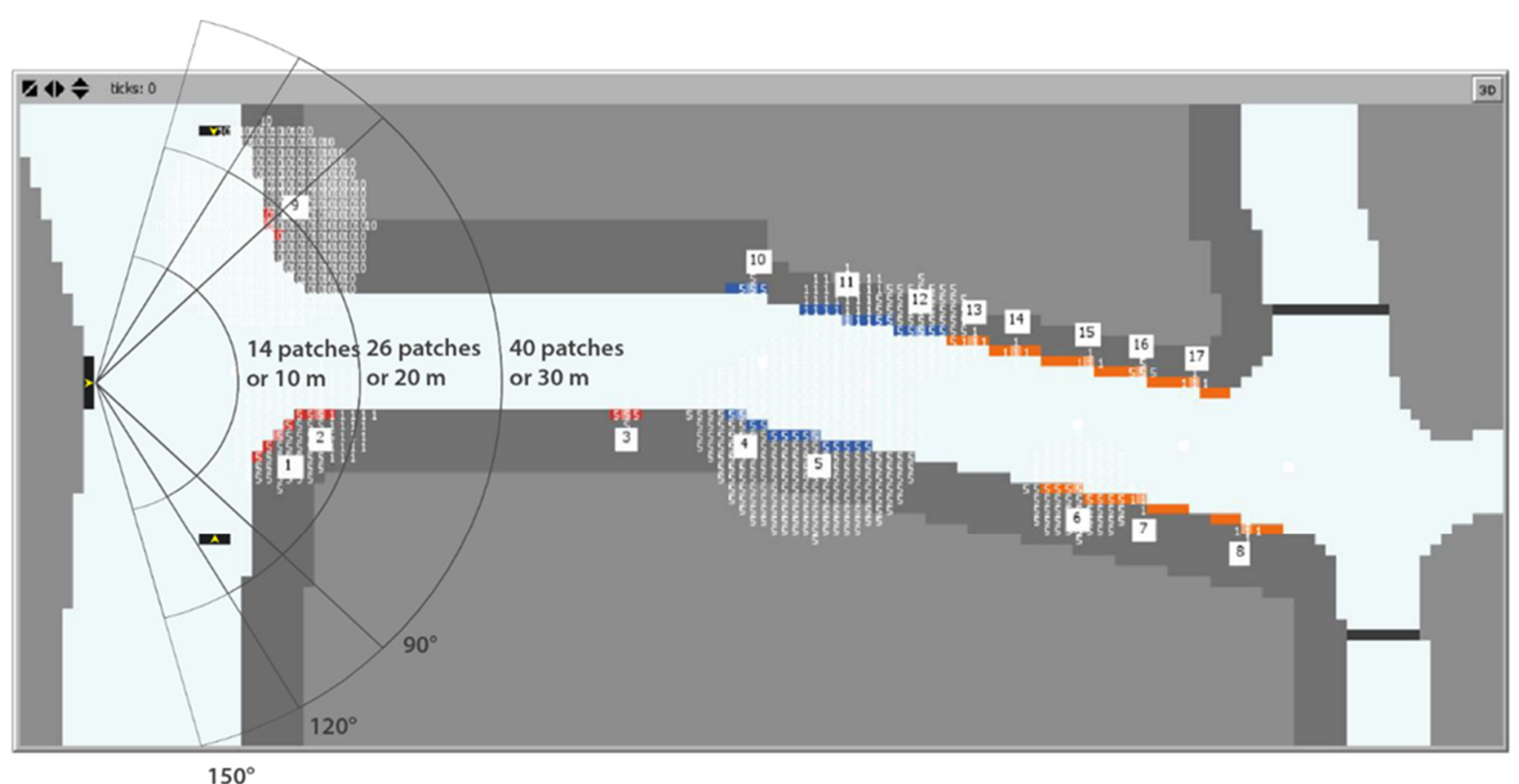

Figure 15. Simulation snapshot showing agent's view angles and vision depths at west entry point. The numbers in the square boxes are the shop numbers.

Figure 16 shows a snapshot from each simulation group with the respective count of attractions per location and a chart to show the average percentage of visits per location for 30 simulations. Simulation group 1 (SG1) shows good results, as all subgroups (SG1a, SG1b, and SG1c) have high average percentages of $40.86 \%, 50.44 \%$, and $43.49 \%$, respectively, for the middle part of the street segment. Then, it is closely followed by the front shop percentages of SG1a and SG1c, but SG1b has a greater percentage difference from the middle shops. The back part of the segment attained the lowest average percentage. Of the three subgroups of SG1, a and c obtained better results because the percentage difference for the front and middle is closer to the observed data. For simulation group 2 (SG2), the average percentages of the simulations were highest for the front shops, followed by the middle and back shops, which had the fewest visits. Simulation group 3 (SG3) produced the worst results, with the front part receiving the most visits. Instead of the front and middle shops being closely related, SG3 produced similar results for the middle and back parts of the street segment. 
Simulation Group 1 (SG1) - vva 90, 120, 150, and vvd 14

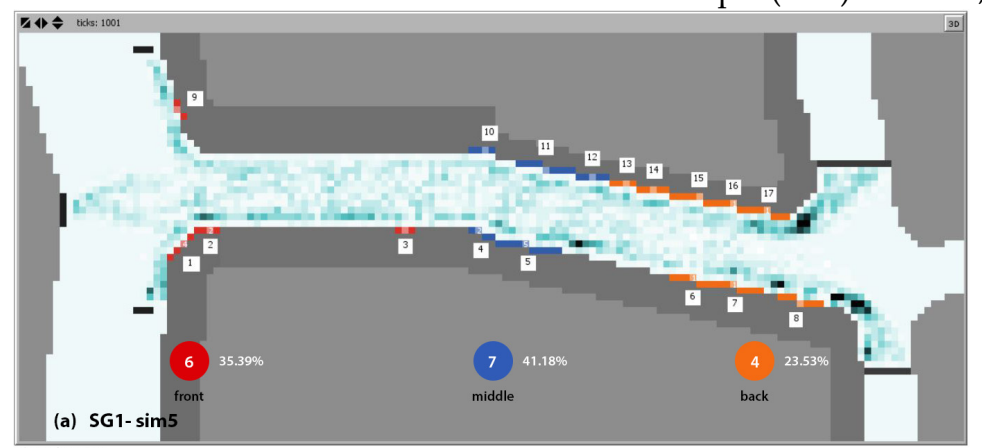

Simulation Group 1 average percentage of visits out

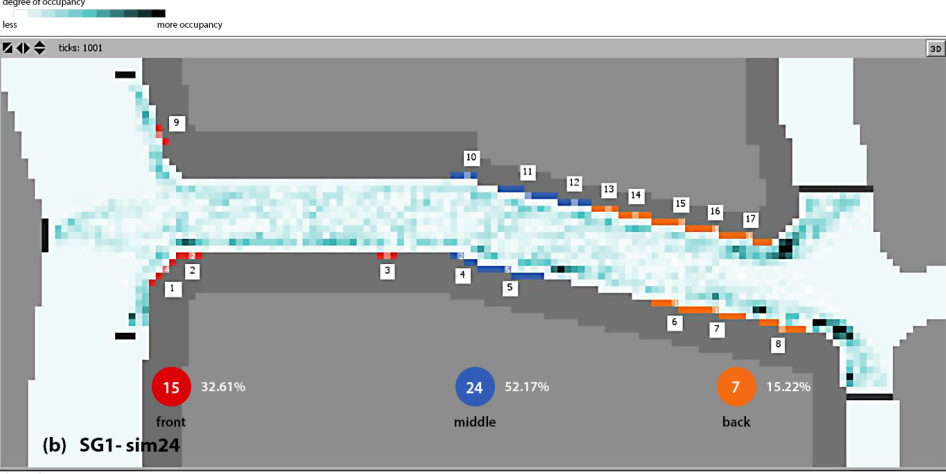
of 30 simulations per subgroup
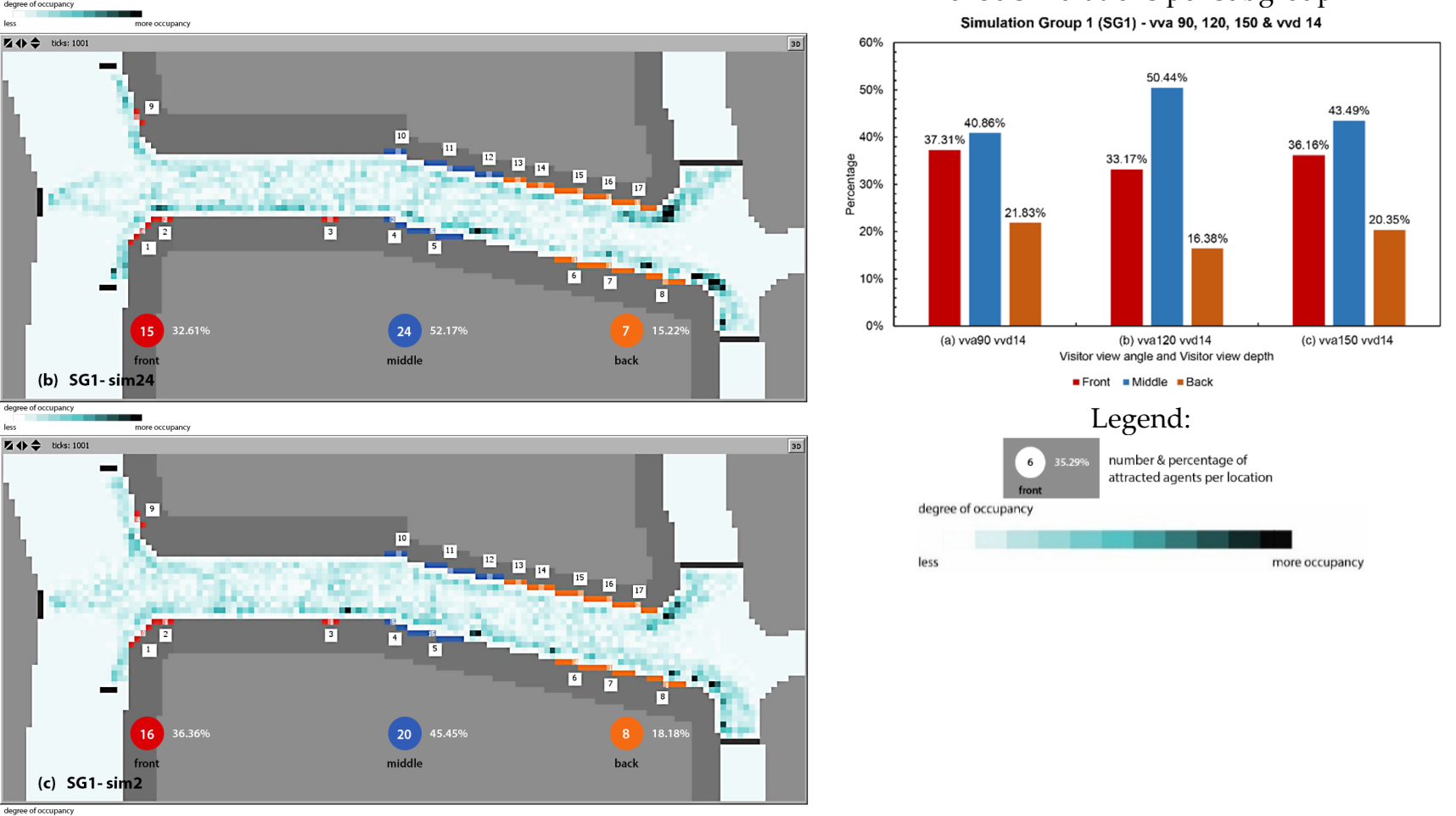

Legend:

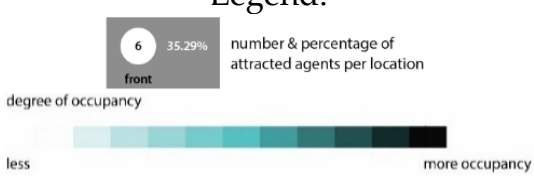

Figure 16. Cont. 
Simulation Group 2 (SG2) - vva 90, 120, 150, and vvd 26

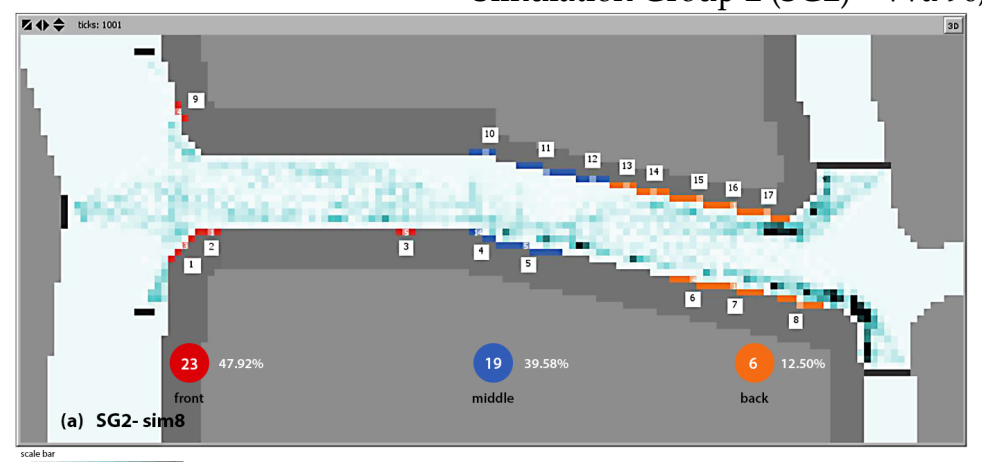

Simulation Group 2 average percentage of visits out of 30 simulations per subgroup
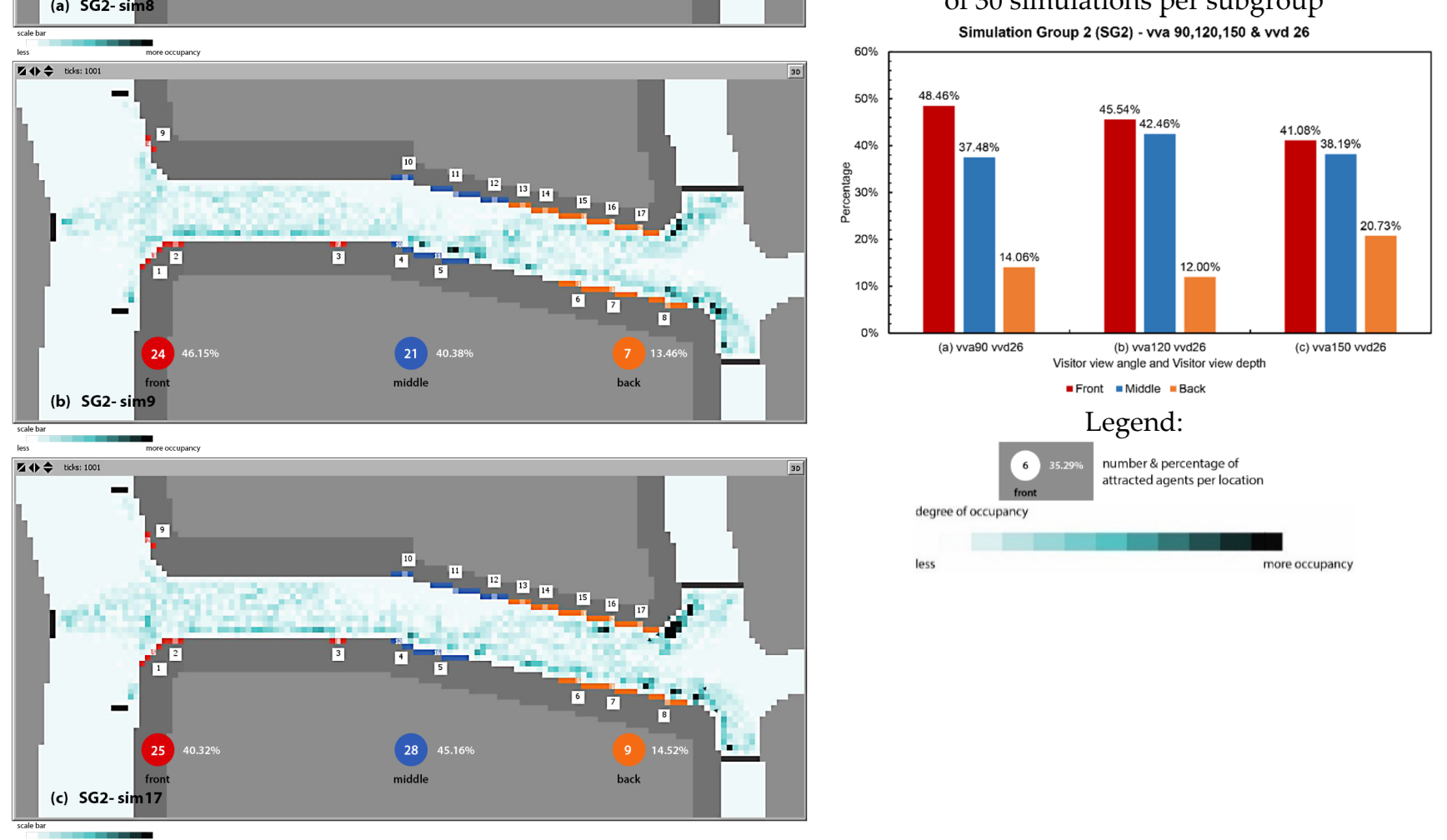

Legend:

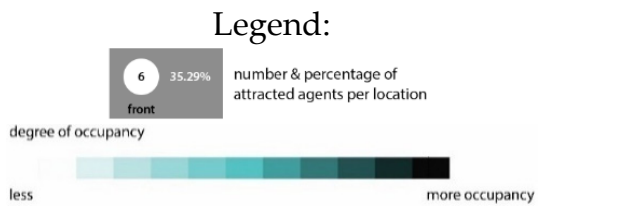

Figure 16. Cont. 
Simulation Group 3 (SG1) - vva 90, 120, 150, and vvd 40

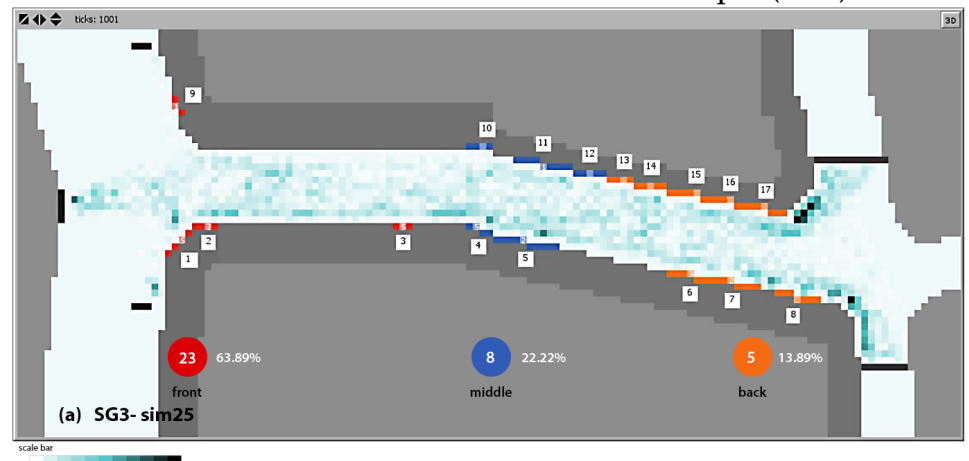

Simulation Group 3 average percentage of visits out

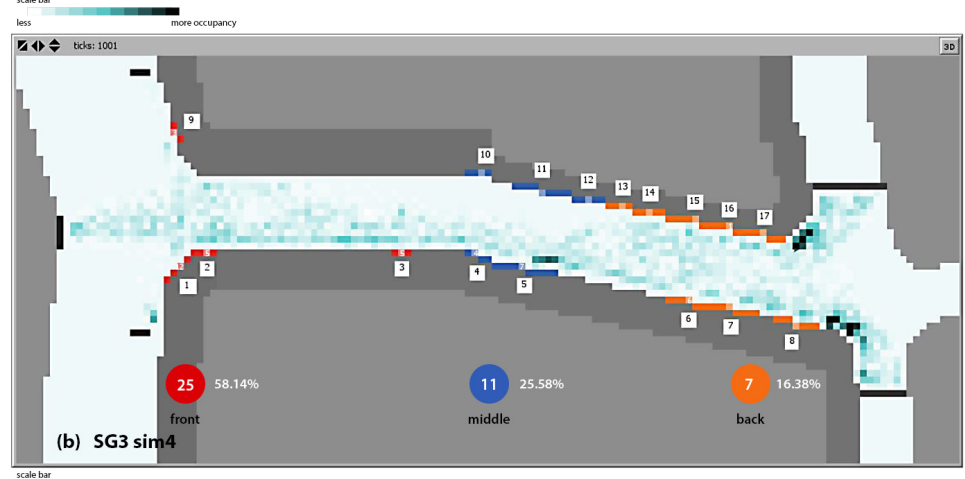
of 30 simulations per subgroup
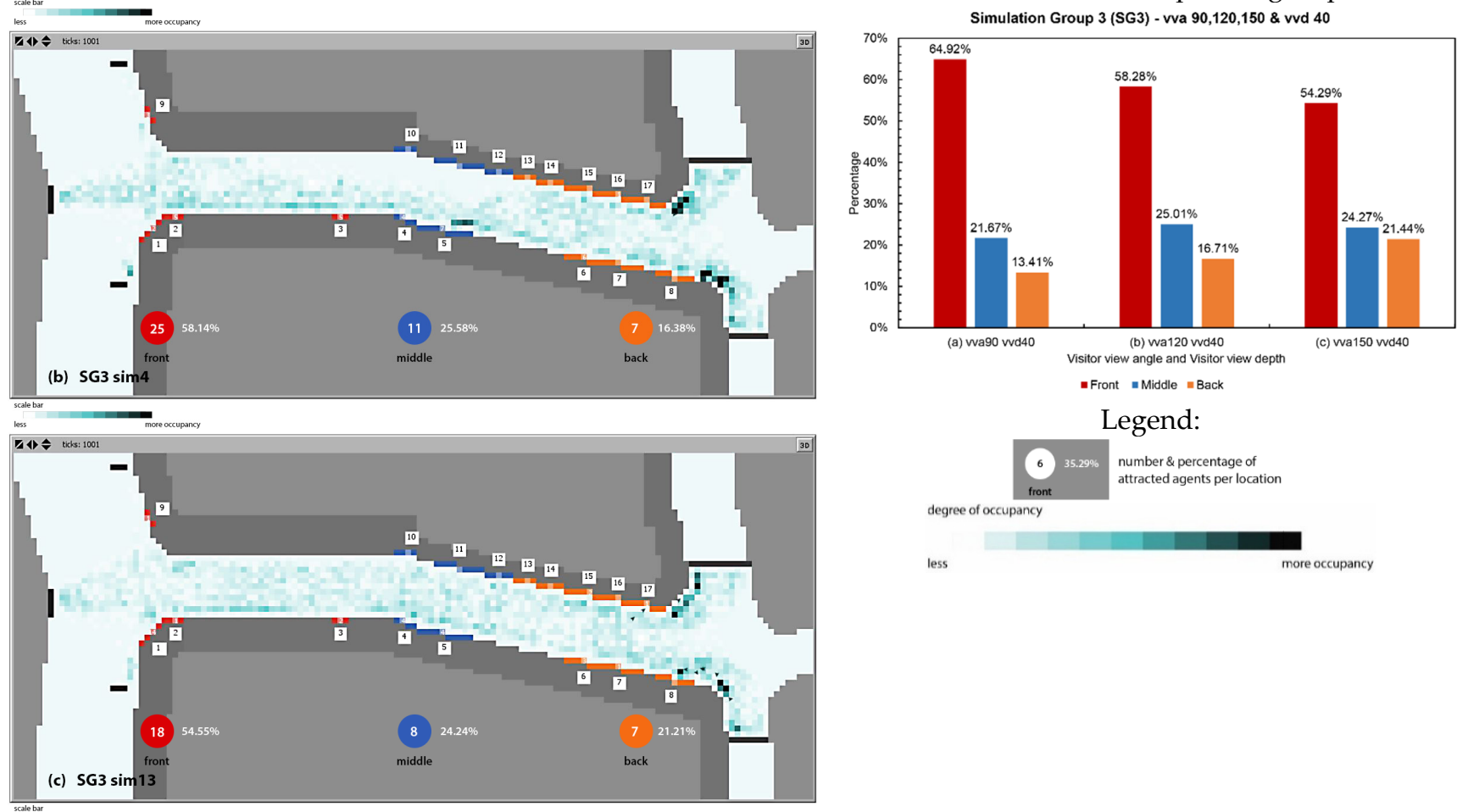
more occupancy

Figure 16. Simulation snapshot and average percentage per subgroup per simulation group. The numbers in the square boxes are the shop numbers.

\subsection{Comparison against the Observed Data}

Comparisons of the observation data and simulation results can help determine whether the simulation model accurately reproduced the visual attraction behavior of pedestrians in the street segment. In Figure 17, the paths of pedestrians in the observed data show a walking preference for the south side (along shops 1 to 8 ) with few pedestrians walking near the north side (along shops 9 to 17). In the middle of the street segment, some pedestrians divert to the north side because pedestrians gather near shops 4 and 5 . Pedestrians proceed to exit separately to the northeast or southeast of the street segment. There are also notable stopovers, such as front shops 1 and 9, middle shops 4, 5, and 10, and back shops 8 and 16. This walking tendency of pedestrians can also be observed in the simulation snapshot (Figure 18). The dark spots in the snapshot indicate that agents have passed through those patches, which translates into higher occupancy. Pedestrian walking preference is also on the south side and is most visible near shops 1 to 3. 


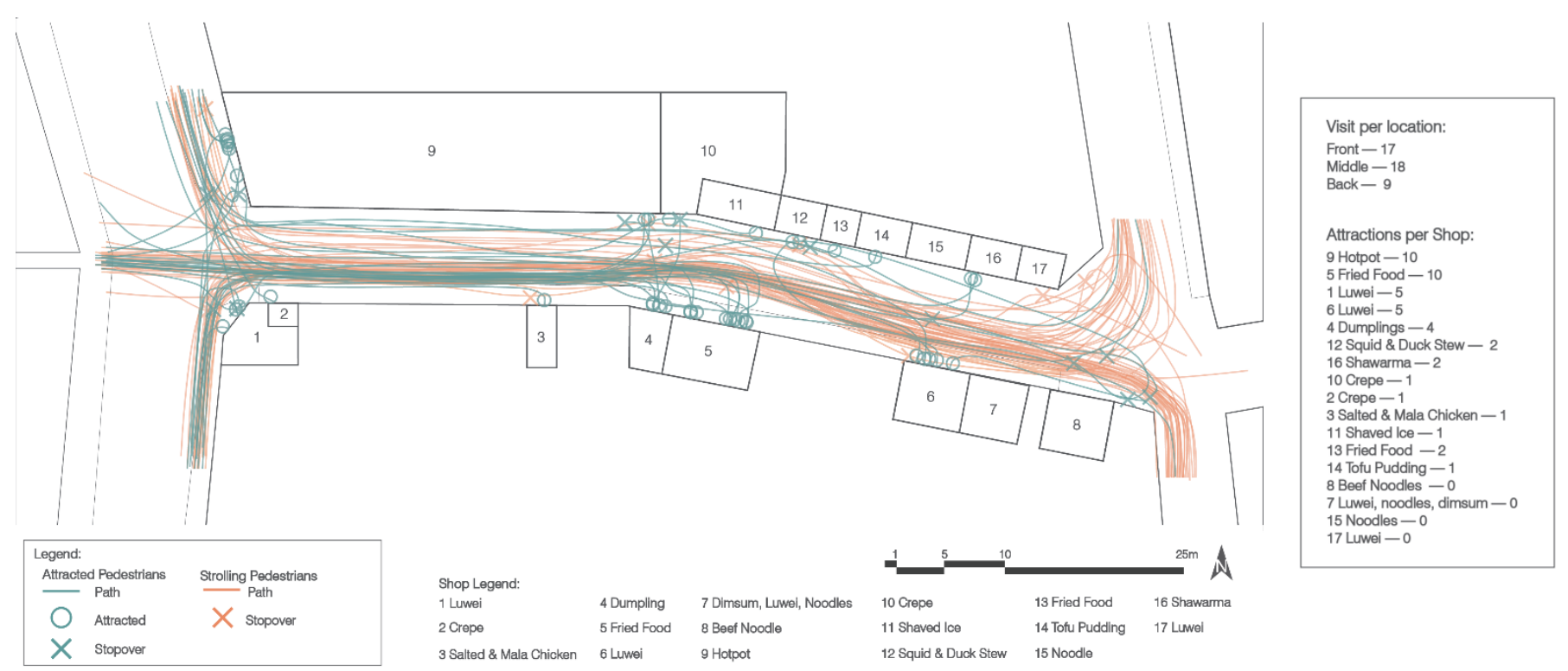

Figure 17. Observed data: pedestrians' paths and attractions (visit) count.

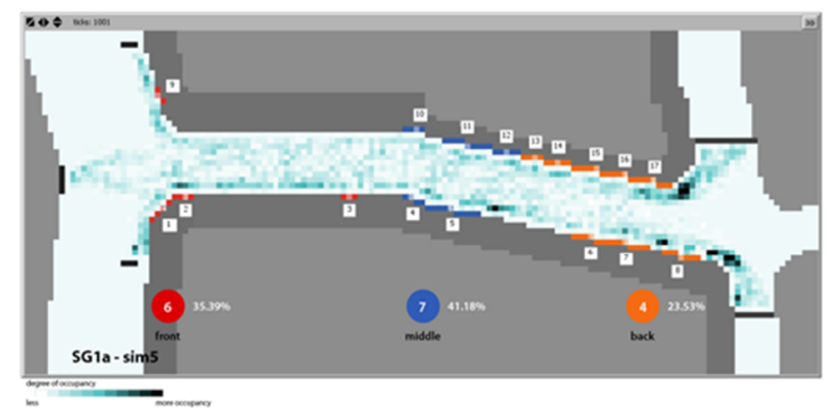

(a)

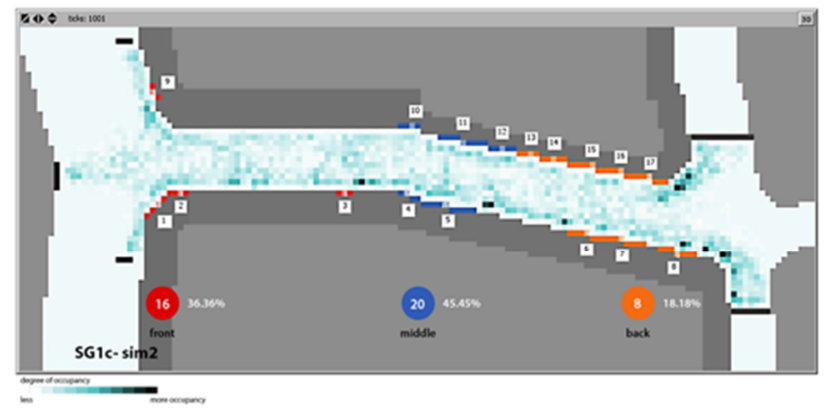

(b)

Figure 18. Visit count per location: simulation snapshot (a) SG1-sim5 with vva90 vvd14 (SG1a) versus simulation snapshot (b) SG1-sim2 with vva150 vvd14 (SG1c).

Although the total number of pedestrians per shop and per location in the observed data and simulation were not entirely equal, SG1 achieved the closest percentage per shop location group, as shown in Figures $2-16$. SG1 had different visitor view angles $\left(90^{\circ}, 120^{\circ}\right.$, and $150^{\circ}$ ) but the same visitor vision depth of 14 patches $(10 \mathrm{~m})$. Despite attaining a slightly lower percentage difference compared to the observed data for SG1a (Figure 19), the narrow $90^{\circ}$ visitor view angle restricts agents from being attracted to the north side of the street segment. A wider view angle of $150^{\circ}$ and a short depth of 14 patches $(10 \mathrm{~m})$ leads to more attractions (visits) to both sides of the street segment, which better emulates the observed pedestrian movement pattern; thus, the parameter configuration of SG1c matched the observed data. 


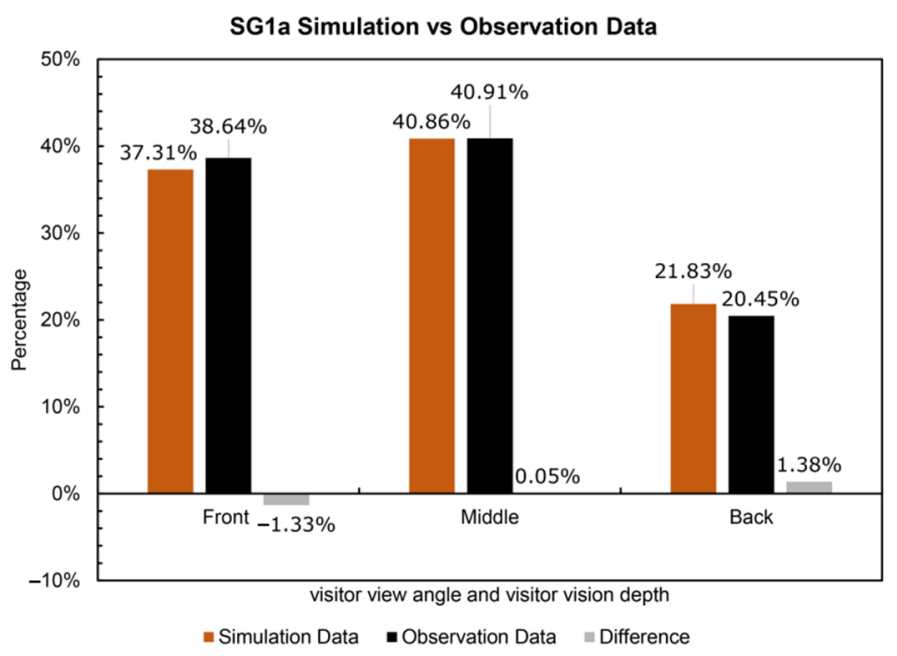

(a)

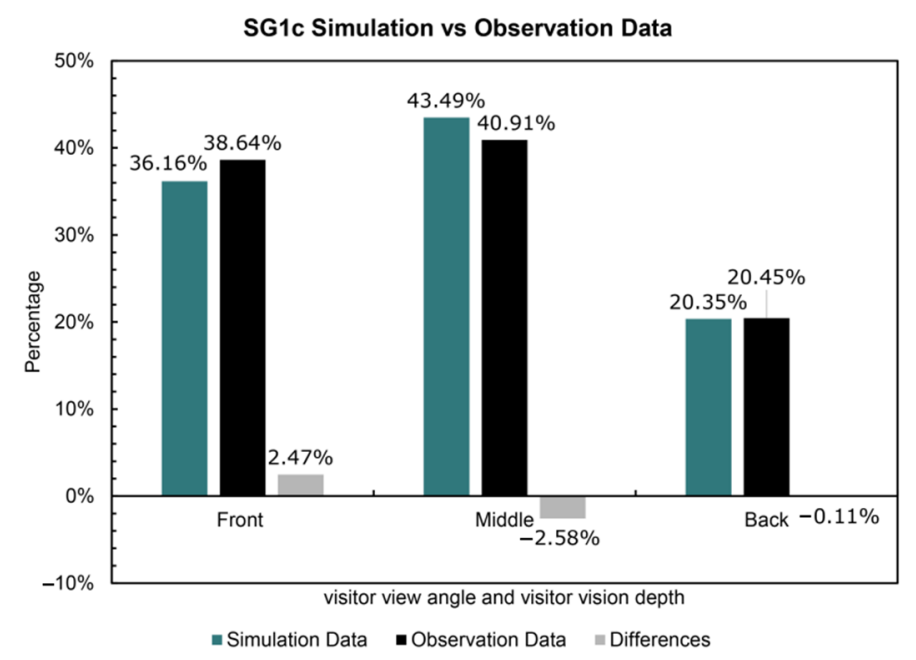

(b)

Figure 19. Chart comparison between simulation vs. observation data: (a) SG1a; (b) SG1c.

\section{Conclusions}

This research introduced a visual attraction model at a microscopic level using NetLogo. The model concentrates on determining the interrelationship of vision, destination attractiveness, and configuration with respect to how pedestrians interact with the environment. The model results are used to determine appropriate parameter values for the pedestrian field of vision and the destination's visibility, attraction level, and influence. Referring to previous studies by Wang [16], goal-oriented and strolling pedestrians were designated as two types of agents in the model. Upon entering the environment, agents have a predetermined destination and engage in exploratory behavior that follows four stages. The fourth stage, the re-evaluation stage (last stage before exiting), is introduced for the purpose of this research. This additional stage allows the agent to reassess the environment after choosing a destination. The agent either chooses another destination or exits.

The new parameters introduced in this model are the settings for the shop's attraction factors. A series of test simulations were conducted to identify the appropriate attraction level and radius of influence for each shop to match the observed data. The parameter composition of the attraction factors for different shops was shown to have a substantial effect on the movement of agents. Thus, appropriate factor settings will result in an accurate representation of the attractions. Moreover, the identification of top shops aids in determining their influence on nearby shops.

The pedestrian's range of vision is limited and disregards some physical elements, such as vertical elements of shops and signage. Different visitor view angles (vva) and vision depths (vvd) were assessed to identify the effective vision range. In terms of the visitor view angle (vva), pedestrians with narrow view angles tend to visit shops on only one side of the market. However, a wider view angle allows pedestrians to visit both sides of the segment. Regarding visitor view depth (vvd), a shorter depth reduces the number of elements being perceived or calculated, which reduces the time and calculations required for determining a destination. Simulated pedestrian movement with $150^{\circ}$ in vva and $10 \mathrm{~m}$ in vvd was validated with the observed data.

The dependability of the visual attraction model is evident, as the simulations emulate the actual shopping behavior of pedestrians strolling along the Shida Night Market street segment with a less than $3 \%$ difference from the observed data. As pedestrians stroll, they casually walk and turn left and right to view possible shop options nearby. In terms of shop location, the front and middle shops have the highest attraction because each area has two top shops. Moreover, being in close proximity to top shops has a positive impact and improves the shop's visibility and profitability. Therefore, the pedestrian's effective vision 
range for the street segment is a wide view angle and short vision depth, which allows pedestrians to assess the environment and available attractors in a leisurely manner.

The current model validates individual pedestrians' shop-sensitive movement behavior based on observed data and is an important step toward an extended agent-based pedestrian movement model that includes multiple visitor group types, group interactions, shop types, and complex spatial configurations.

Qualitative data from long-term observations may further validate some general concepts, such as frequent visitors and tourists having different perceptions of shop attractiveness, the changing popularity of the shop over time, and new shops attracting more curious visitors. These findings will give rise to the extended version of the "destination attractiveness" function for broader applications of the proposed pedestrian movement model.

Author Contributions: Conceptualization, Y.-S.C.; methodology, Y.-S.C. and A.Y.B.; software, Y.-S.C. and A.Y.B.; validation, A.Y.B.; formal analysis, Y.-S.C. and A.Y.B.; investigation, A.Y.B.; resources, Y.-S.C.; data curation, Y.-S.C. and A.Y.B.; writing-original draft preparation, Y.-S.C. and A.Y.B.; writing-review and editing, Y.-S.C.; visualization, A.Y.B.; project administration, A.Y.B.; funding acquisition, Y.-S.C. All authors have read and agreed to the published version of the manuscript.

Funding: This research was funded by the Taiwan Ministry of Education "University Social Responsibility" Project.

Institutional Review Board Statement: Ethical review and approval were waived for this study. This study mapped pedestrian movement in the public area. The human subjects are not identifiable. This study has neither intervention nor interaction with the human subjects.

Informed Consent Statement: Not applicable.

Data Availability Statement: The time-lapse clips of the pedestrian movement are available on request from the corresponding author with the consent from the funding agency.

Acknowledgments: The authors would like to thanks the members of the ISAAC lab for the assistance in the field observation.

Conflicts of Interest: The authors declare no conflict of interest.

\section{References}

1. Chang, J.; Heish, A.T. Leisure motives of eating out in Night Markets. Bus. Res. 2006, 59, 1276-1278. [CrossRef]

2. Iqbal, M.; Karsono, B.; Atthaillah, A.; Lisa, N.P. Night Market Contribution to Sustainability of Urban Spaces. Pertanika J. Soc. Sci. Hum. 2017, 25, 131-138.

3. Kuo, C.T.; Chung, M.L.; Kuo, F.C. To Explore Taiwaneses Night Markets Culture and Tourism Experience and Behavior. Soc. Behav. Sci. 2012, 40, 435-440. [CrossRef]

4. Taiwan Tourism Bureau. Available online: https://admin.taiwan.net.tw/ (accessed on 30 October 2020).

5. Lee, S.H.; Chang, S.C.; Hou, J.S.; Lin, C.H. Night Market experience and image of temporary residents and foreign visitors. Int. J. Cult. Tour. Hosp. Res. 2008, 2, 217-233. [CrossRef]

6. Crooks, A.; Croitoru, A.; Lu, X.; Wise, S.; Irvine, J.M.; Stefanidis, A. Walk This Way: Improving Pedestrian Agent-Based Models through Scene Activity Analysis. ISPRS Int. J. Geo-Inf. 2015, 4, 1627-1656. [CrossRef]

7. Park, J.H.; Rojas, F.A.; Yang, H.S. A collision avoidance behavior model for crowd simulation based on psychological findings. Comput. Animat. Virtual Worlds 2013, 24, 173-183. [CrossRef]

8. Moussaï, M.; Helbing, D.; Theraulaz, G. How simple rules determine pedestrian behavior and crowd disasters. Proc. Natl. Acad. Sci. USA 2011, 108, 6884-6888. [CrossRef]

9. Asano, M.; Iryo, T.; Kuwahara, M. Microscopic pedestrian simulation model combined with a tactical model for route choice behaviour. Transp. Res. Part C Emerg. Technol. 2010, 18, 842-855. [CrossRef]

10. Gibson, J.J. The Ecological Approach to Visual Perception; Houghton Mifflin: Boston, MA, USA, 1979.

11. Hillier, B.; Penn, A.; Hanson, J.; Grajewski, T.; Xu, J. Natural Movement: Or, Configuration and Attraction in Urban Pedestrian Movement. Environ. Plan. B Plan. Des. 1993, 20, 29-66. [CrossRef]

12. Turner, A.; Penn, A. Encoding natural movemnt as an agent-based system: An investigation into human pedestrian behavior in the built environment. Environ. Plan. B Plan. Des. 2002, 9, 473-490. [CrossRef]

13. Lee, S.J.; Lee, K.H.; Kang, S.J. Study on a Pedestrian Simulation Model of Natural Movement. AJ. Asian Arch. Build. Eng. 2013, 12, 41-48. [CrossRef]

14. Lee, S.-J. Navigational Pedestrian Movement Model with Vision-driven Agents. J. Asian Arch. Build. Eng. 2015, 14, 371-378. [CrossRef] 
15. Martella, C.; Miraglia, A.; Frost, J.; Cattani, M.; van Steen, M. Visualizing, clustering, and predicting the behavior of museum visitors. Pervasive Mob. Comput. 2017, 38, 430-443. [CrossRef]

16. Wang, W.L.; Lo, S.M.; Liu, S.B.; Kuang, H. Microscopic modeling of pedestrian movement behavior: Interacting with visual attractors in the environment. Transp. Res. Part C Emerg. Technol. 2014, 44, 21-33. [CrossRef]

17. Werberich, B.R.; Pretto, C.; Cybis, H. Pedestrians' Route Choice Model for Shopping Behavior. In Proceedings of the Ninth International Workshop on Agents in Traffic and Transportation (ATT 2016) co-located with the 25th International Joint Conference on Artificial Intelligence (IJCAI 2016), New York, NY, USA, 10 July 2016.

18. Open Street Map. Available online: https:// www.openstreetmap.org/ (accessed on 30 October 2020).

19. Bogers, A.; Kemperman, Q.; Timmermans, H. Modeling Pedestrian Movement in Shopping Street Segments. In Pedestrian Behavior; Emerald Group Publishing Limited: Bingley, UK, 2009; Chapter 5; pp. 87-111.

20. U. Wilensky NetLogo Webpage. Available online: https://ccl.northwestern.edu/netlogo (accessed on 30 October 2020).

21. Grimm, V. Individual-based Models. In Encyclopedia of Ecology; Elsevier Science: Amsterdam, The Netherlands, 2008; pp. 1959-1968.

22. Sutherland, D.H.; Kaufman, K.R.; Moitoza, J.R. Kinematics of normal human walking. In Human Walking; Rose, J., Gamble, J.G., Eds.; Williams and Wilkins: Baltimore, MD, USA, 1994; pp. 23-44.

23. Gibson, E. Exploratory behavior in the development of perceiving, acting, and the acquiring of knowledge. Annu. Rev. Psychol. 1988, 39, 1-42. [CrossRef] 